\title{
CONTRIBU'TION TO THE ANATOMY OF THE CHINESE FINLESS PORPOISE, NEOMERIS PHOCAENOIDES
}

\author{
By A. Brazier Howell
}

Of the Bureau of Biological Survey, United States Department of Agriculture

\section{INTRODUCTION}

Among the spirit specimens of mammals in the United States National Museum are several of the Chinese black finless porpoise, Neomeris phocaenoides (Cuvier), which were presented to the Museum by the National Geographic Society in collections made by F. R. Wulsin. Certain osteological features of one of these porpoises were investigated by Remington Kellogg in connection with another problem and his dissections indicated that unless some immediate use were made of these specimens they would soon be worthless for any studies of the soft parts. The matter was brought to the attention of Gerrit S. Miller, jr., and he generously permitted the writer to make whatever disposition of the material might seem to him best. It was at first thought that the preservation was too poor to permit of a dissection sufficiently accurate to be of great value, but it was later found that although the condition was far from satisfactory and such as to preclude fine work, observations of decided interest were nevertheless being made upon the first specimen which was being somewhat hastily examined, and in consideration both of the rarity of this porpoise in the collections of the world and the place in the research program of the writer of the investigation of aquatic adaptations, it was decided that these should be presented in print. A more careful and detailed dissection of a second specimen was accordingly undertaken by the author, and upon this the present contribution is based.

The lot of spirit specimens under consideration had been slit from the vent to the throat and immersed in alcohol which had failed to penetrate sufficiently for proper preservation. Before the arrest of decomposition the deeper portions of the larger muscle masses had become putrid, and when cut into the coarser fibers separated at a touch,

No. 2662.-Proceedings U. S. National museum, Vol 70, Art. I3. $20442-27--1$ 
so that the technique of dissection was necessarily very bad. It can not be claimed that every one of the smaller muscles was differentiated. When a point was at all doubtful, however, mention is made of the fact, and by working carefully and noting the direction of the fibers, it is felt that even when the muscles were in too bad a state to be properly handled the results of the dissection are sufficiently accurate for all practical purposes. It seems needless to say that the dissection of material in such a state of preservation should rarely be attempted, but cetacean material that is suitable for myological study so seldom comes to hand that advantage should be taken of every opportunity.

An adequately thorough investigation of specialization for an aquatic existence among the Mammalia calls for a study of the anatomy of representatives of a number of orders. On account of the present lack of desired material, however, and because it is unlikely that this can be secured in the immediate future, the present contribution will be offered separately and without discussion.

\section{HISTORICAL}

The latest paper of any length dealing with Neomeris is that of Glover M. Allen (1923). In this its generic and specific history is clearly and adequately presented, so that further discussion of this item would constitute mere repetition. Allen employs, however, the generic name Meomeris, which Thomas (1925) has discarded in favor of Neomeris, an action entirely in accord with the opinion of the present writer.

\section{MATERIAL}

Exclusive of those in the United States National Museum there are evidently no more than a dozen specimens of this porpoise preserved in the institutions of the world, and several of these are fragmentary and undoubtedly in a very poor state of preservation. The National Museum material, however, is more comprehensive than all the remainder combined. This material is as follows:

\section{Alcoholics :}

240862, ${ }^{1}$ im. female. Woosung, Kiangsu, China. May 24, 1924. F. R. Wulsin.

240863, juv. female. Woosung, Kiangsu, China. Mar. 20, 1924. F. R. Wulsin.

240866, im. female. Woosung, Kiangsu, China. May, 1924. F. R. Wulsin. 240864, im. female. Yangtze, Kiangsu, China. Mar. 26, 1924. F. R. Wulsin.

240865, ad. female. Whangpoo Cr., Kiangsu, China. April, 1924. F. R. Wulsin.

239611, juv. male. Yochow, Hunan, China. May 20, 1923. ' C. M. Hoy. 
Skeletons :

49544, sex (?). No history.

240862, ${ }^{1}$ im. female. Woosung, Kiangsu, China. May, 1924. F. R. Wulsin. 240001, sex (?). Woosung, Kiangsu, China. May 5, 1923. F. R. Wulsin. 240002, sex (?). Woosung, Kiangsu, China. May 5, 1923. F. R. Wulsin. 240002, sex (?). Woosung, Kiangsu, China. April 25, 1923. F. R. Wulsin. 240003, sex (?). Woosung, Kiangsu, China. April 10, 1923. F. R. Wulsin. 239990, sex (?). Hokudo, Zenra Prov., Korea. June 20, 1923. Doctor Ishikawa.

For the present study there have thus been available 11 specimens. $^{1}$ Those collected by F. R. Wulsin were gifts to the Museum from the National Geographic Central China Expedition, and the individual secured by C. M. Hoy was obtained during the Chinese expedition sent out by Dr. W. L. Abbott.

The myological portion of the present contribution is based upon the dissection of two of the immature females, which apparently were fully developed sexually but were smaller than any other cleaned skeleton available. Number 240864 was the first one dissected, and the parts in the worst condition were passed over with but cursory attention. Number 240862 was the one next investi gated.

\section{EXTERNAL FEATURES}

Measurements.-For the reasons that Allen (pp. 244-245) has already given such a detailed list of external measurements of one of the specimens which he investigated, and that these are deemed to be of slight value when taken from specimens that have been preserved and varyingly distorted, but few measurements are here presented (in millimeters).

\begin{tabular}{|c|c|c|c|c|}
\hline (250) & 240865 & 240864 & 240862 & 240863 \\
\hline Length to fluke notch. & 1,348 & 948 & 964 & 600 \\
\hline Circumference of peduncle. & 158 & 127 & 132 & 96 \\
\hline Width of flukes & 392 & 255 & 270 & 150 \\
\hline Length of right flipper from axilla & 219 & 133 & 172 & 110 \\
\hline Width across mouth & 98 & 87 & 82 & 60 \\
\hline
\end{tabular}

Color--Observations concerning the color of alcoholic material may be of little value. Be that as it may, the adult female before me is very dark sooty, almost black, as is the Wulsin juvenile, and these two are uniformly of a single shade. All of the remaining specimens, on the contrary, are considerably lighter, the hide being suggestive in color and appearance of a piece of boiled liver, but smoother. Especially when dry the underparts of these immatures are definitely lighter than the more dorsal area, the dividing line,

\footnotetext{
${ }^{1}$ Number 240862 , as an alcoholic, was dissected and the skeleton then cleaned.
} 
which is indistinct, extending from the vicinity of the eye to about $25 \mathrm{~mm}$. above the flipper, and then running in a straight line to a point midway between the anus and the lateral base of the flukes. The hide appears glossy when wet and dull when dry, and is very thin and probably pliable, although naturally it is hardened by the action of the preservative.

General form.-Reference to Figure 1 (drawn with the aid of a Wollaston prism and then corrected for symmetry) will give a better idea of the general form than can a printed description. The bulge of the forehead lends an appearance of anterior heaviness to the body, and there is no depression in the vicinity of the neck, although such may be present in the preserved animal, due to a cramped position after death.

Head.-The lips are rounded and horny, and the whole anterior part of the head, save posterior to the corners of the mouth and at the apex of the frontal prominence, is tough and elastic to the touch, something like a well-inflated pneumatic tire. Even the corners of the mouth are sufficiently hard to cause one to wonder how free movement of the lower jaw is possible, as of course must be the case. There is a slight depression which appears posterior to the chin when the mouth is open.

The eye is very small, the distance between the canthi of an immature measuring but $12 \mathrm{~mm}$., and the eyeball is set flush with the surface of the cheek. The eyes are open in the preserved specimens, and yet the upper and lower lids are unwrinkled, as it seems they should be were they fully functional. In addition, the tissue about the eye is so fibrous that it is obvious that the mobility of this region is impaired to an indeterminate extent.

The subdermal portion of the external auditory tube is indicated by a slight depression or dimple in the integument, which in the last. animal dissected was $111 \mathrm{~mm}$. posterior to the angle of the mouth, a line extending between these two points running just below the eye. The external opening is minute, but the auditory tube broadens subdermally and is curved as indicated in Figure 11.

The apex of the frontal prominence yields more readily to manual pressure than do other portions of the head because of the presence beneath this spot of a deposit of soft fat. The blowhole is situated a trifle caudad of a line running directly vertical through the eye. It is $22 \mathrm{~mm}$. in transverse measurement and slightly crescentric, the concave aspect facing craniad. The edges are lightly rounded.

Anterior limb. - The flipper or anterior limb varies considerably in relative size. Thus in the adult female the right flipper was 16 per cent of the total length, in one of the immatures dissected, 14 per cent; and in the other immature investigated and the Wulsin 
juvenile, 18 per cent. The proportions, however, were very similar in all the animals. The anterior margin of the flipper is evenly curved, while the posterior margin is "wavy," the border projecting
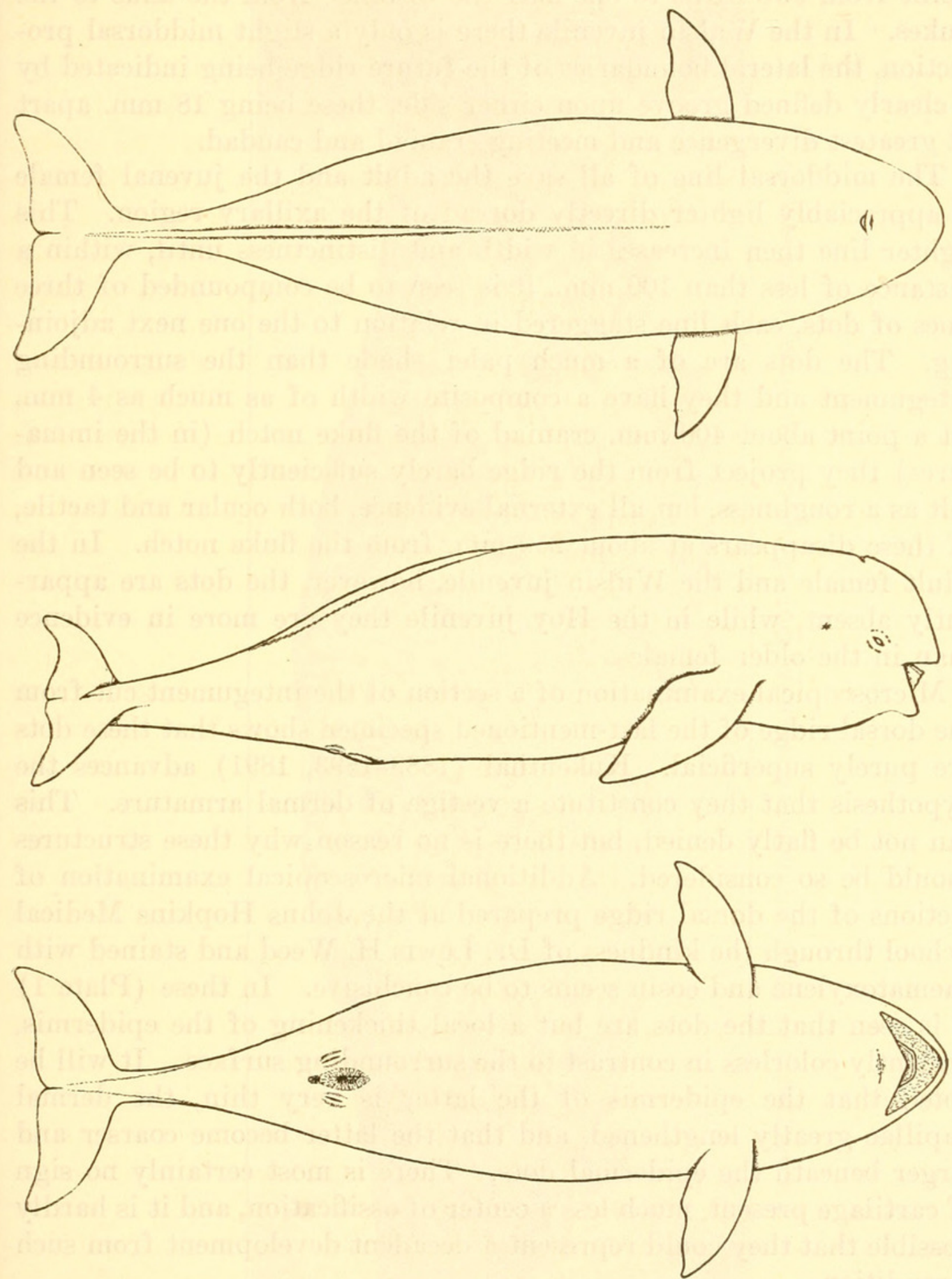

Fig. 1.-External aspect of neomeris. Upper, dorsal view; middle, lateral view OF RIGHT SIDE; LOW.ER, VENTRAL VIEW

somewhat near the extremity of each digit and receding between these points.

Dorsal ridge.-The anterior extremity of the dorsal ridge rises very gradually, becoming distinguishable at a point about midway 
of the dorsum. In the adult female it reaches a height of about 23 $\mathrm{mm}$., and $19 \mathrm{~mm}$. in the immatures; but this measurement is impossible to take with precision. It then disappears as a true ridge at a point from two-fifths to one-half the distance from the anus to the flukes. In the Wulsin juvenile there is only a slight middorsal projection, the lateral boundaries of the future ridge being indicated by a clearly defined groove upon either side, these being $18 \mathrm{~mm}$. apart at greatest divergence and meeting craniad and caudad.

The middorsal line of all save the adult and the juvenal female is appreciably lighter directly dorsad of the axillary region. This lighter line then increases in width and distinctness until, within a distance of less than $100 \mathrm{~mm}$., it is seen to be compounded of three lines of dots, each line staggered in relation to the one next adjoining. The dots are of a much paler shade than the surrounding integument and they have a composite width of as much as $4 \mathrm{~mm}$. At a point about $400 \mathrm{~mm}$. craniad of the fluke notch (in the immatures) they project from the ridge barely sufficiently to be seen and felt as a roughness, but all external evidence, both ocular and tactile, of these disappears at about $250 \mathrm{~mm}$. from the fluke notch. In the adult female and the Wulsin juvenile, however, the dots are apparently absent, while in the Hoy juvenile they are more in evidence than in the older females.

Microscopical examination of a section of the integument cut from the dorsal ridge of the last-mentioned specimen shows that these dots are purely superficial. Kükenthal (1889-1893, 1891) advances the hypothesis that they constitute a vestige of dermal armature. This can not be flatly denied, but there is no reason why these structures should be so considered. Additional microscopical examination of sections of the dorsal ridge prepared at the Johns Hopkins Medical School through the kindness of Dr. Lewis $\mathrm{H}$. Weed and stained with haematoxylene and eosin seems to be conclusive. In these (Plate 1) it is seen that the dots are but a local thickening of the epidermis, evidently colorless in contrast to the surrounding surface. It will be noted that the epidermis of the latter is very thin, the dermal papillae greatly lengthened, and that the latter become coarser and larger beneath the epidermal dots. There is most certainly no sign of cartilage present, much less a center of ossification, and it is hardly possible that they could represent a decadent development from such a condition.

Flukes.-In one of the females dissected the peduncle was $24 \mathrm{~mm}$. wide at the narrowest point and $57 \mathrm{~mm}$. in height. The dorsal border of the peduncle is sharper or more acute than is the ventral border. The flukes are symmetrically placed and their width varies from 27 and 28.6 per cent of the total length of the immatures to 29 


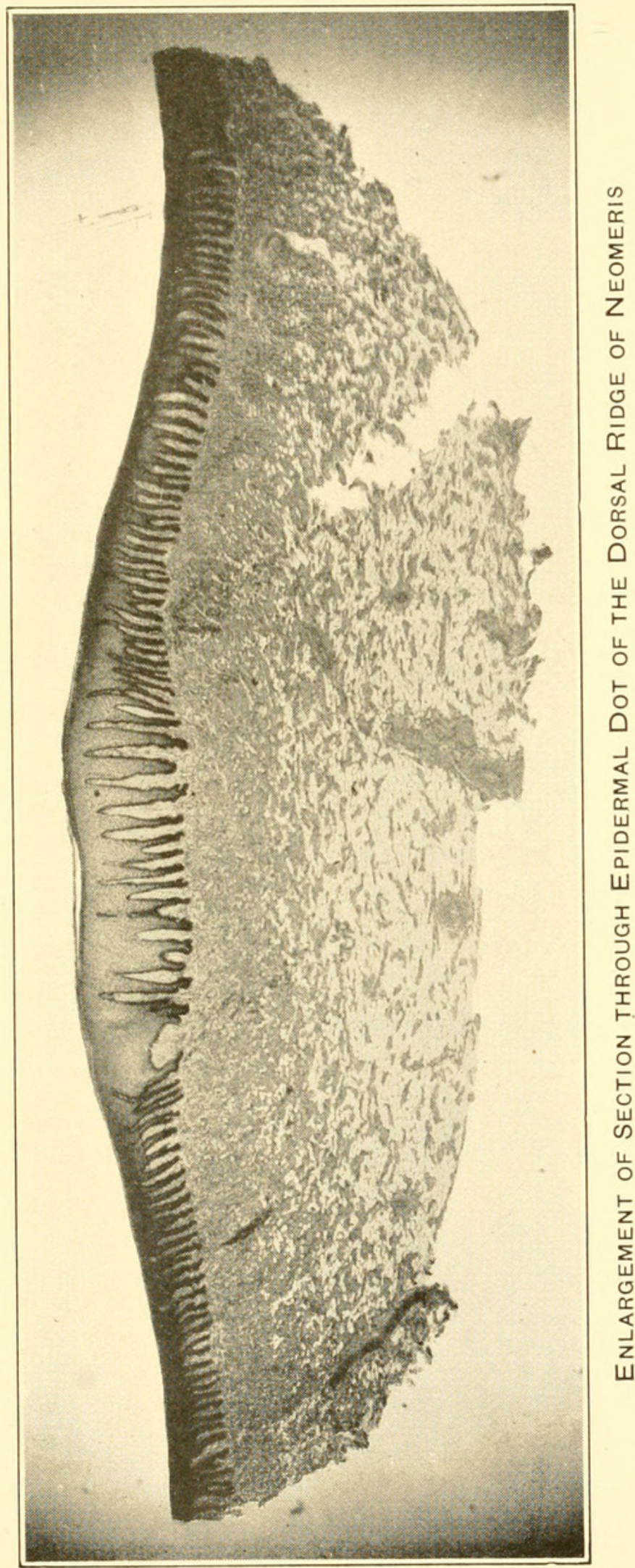



per cent in the adult female. The notch between the flukes of the former is deep and narrow, the sides in fact overlapping; but in the adult the notch is much broader and relatively not so deep.

Genitalia.-In lateral profile the position of the vulva is indicated by a slight though definite prominence, and the position of the anus by another that is barely apparent. There is a pair of labia, which are hardened in the preserved specimens, and not approximated. Between them lies the vulva, the external features of which are of generous size, but there is no clitoris to be seen. Caudad is situated the much smaller anal opening.

Mammae.-Upon either side and barely caudad of the vulval orifice, as indicated in Figure 1, is a mammary silt, barely raised above the surrounding surface. The borders are lightly marked by depressions.

\section{OSTEOLOGY}

Allan's descriptions and comparisons of the skeleton of Neomeris with that of Phocaena are adequate, and a repetition of the information which he presents is hardly desirable; but supplementary and additional details are herewith offered.

SKULL

As is to be expected, the skulls exhibit endless variation of a somewhat minor nature, especially in the development of the intermaxillary prominences, the region about the external nares, and the rostrum. Caudad, the middorsal sulcus of the rostra of two specimens, is slightly curved, the convex portion facing to the right in 240001 and to the left in 240003. The right side of the skull, from the dorsal aspect, is invariably a trifle larger than the left, as shown by the accompanying measurements. These are taken transversely from the dorso-caudal termination of the mesethmoid to the lateral border of the maxilla of either side. In the cleaned skulls the two narial apertures are practically the same size. As mentioned in the discussion of the blowhole, there is a fossa, filled by a corresponding dilation of the adjoining spiracle, upon the medial portion of the maxilla immediately latero-caudad of the narial opening, and that of the right side is distinctly larger than of the left, save in 49544, in which the two are similar. The vertex of this specimen exhibits the least cranial projection, and as the largest fenetrations of the exoccipitals (save in the immature female dissected and cleaned) are also present in this skull, which is considerably the largest, it is likely that it is a male, while the remaining skeletons are of females.

Upon the ventral aspect of the skull there is variation in the conformation of the border of the palate and the adjoining portion of the pterygoids. There is also variation in the distance that the 
falcate processes extend ventrad of the floor of the basioccipital, and apparently infinite variety in the development and shape of the lateral border of the exoccipital. The most important detail of this variation, from a functional standpoint, is the distance from the condyle to the lateral border of the exoccipital, the difference exhibited being as great as $20 \mathrm{~mm}$., thus altering by just this degree the leverage of the attached muscles. Worthy of note is the smoothness of the occipital region as a whole and the large capacity of the brain case. There is a great variation in the intercondyloid portion of the basioccipital, as in 240003 this measures $8.5 \mathrm{~mm}$., and in

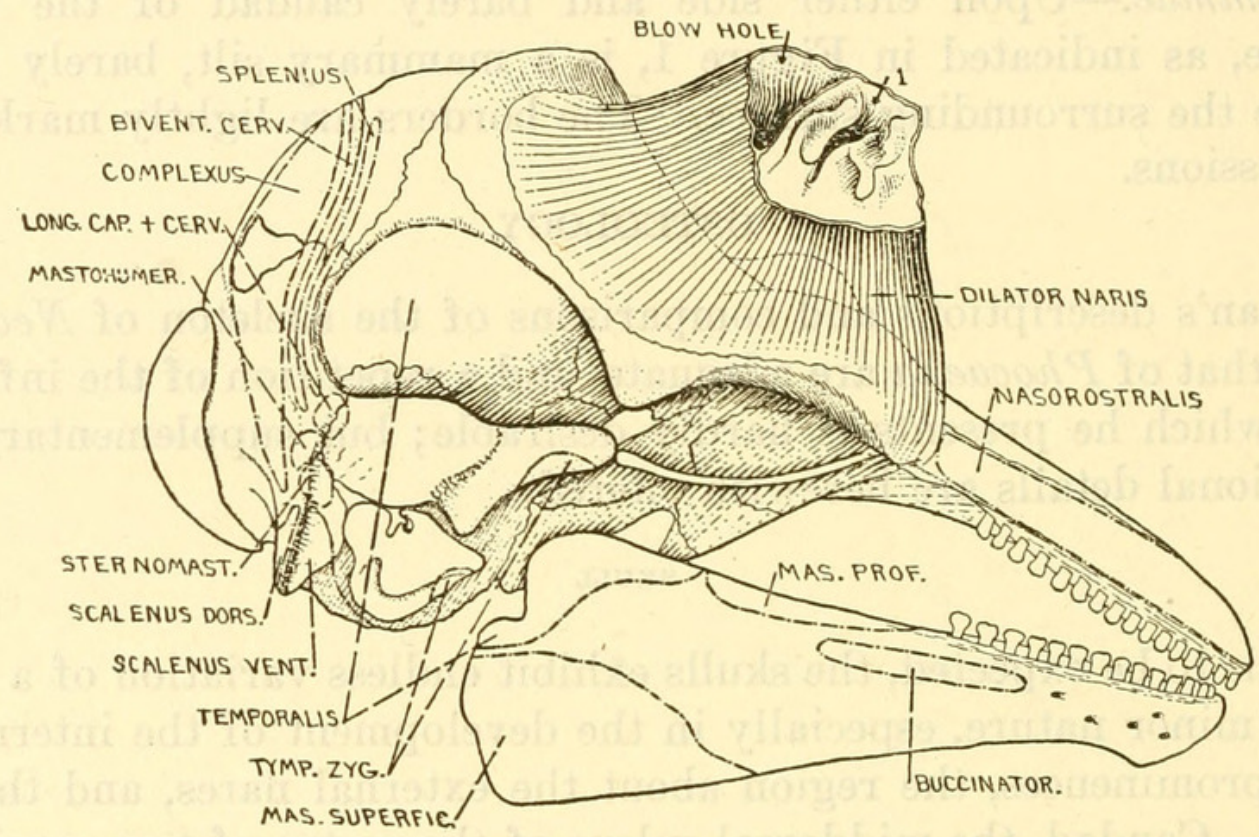

Fig, 2.-Lateral aspect of right Side of the SKull of neomeris, SHOWING PARTIAL DISSECTION OF SUPERFICIAL RESPIRATORY SAC (ARROW 1 POINTING TO ITS PASSAGE OF COMMUNICATION WITH THE BLOWHOLE) ; THE SECOND LAYER OF SPIRACULAR MUSCULATURE; AND ATTACHMENTS OF THE MUSCLES TO THIS PART OF THE SKULL

$240002,20 \mathrm{~mm}$. in width; but in these two specimens the total condyloid width is approximately equal. The bone of the more central portion of the basioccipital is so thin that in 240001 and 240003 , and to a lesser extent in 240002 , there are extensive vacuities here.

Measurements of cranial details (in millimeters)

\begin{tabular}{|c|c|c|c|c|c|c|}
\hline Detail of skull & 239990 & 240001 & 240002 & 240003 & 240862 & 49544 \\
\hline Total length of skull & 220 & 208 & 222 & 213 & 188 & 2 \\
\hline Greatest height_. & 104 & 97 & 99 & 98 & 99 & \\
\hline Greatest width & 141 & 142 & 144 & 141 & 129 & 10 \\
\hline $\begin{array}{l}\text { Width of rostrum at anteorbital } \\
\text { notch }\end{array}$ & 71 & 66 & 65 & 64 & 56 & \\
\hline $\begin{array}{l}\text { Middle mesethmoid to border right } \\
\text { maxilla }\end{array}$ & 63 & 64 & 67 & 62 & 60 & \\
\hline $\begin{array}{l}\text { Middle mesethmoid to border left } \\
\text { maxilla }\end{array}$ & 55 & 56 & 60 & 55 & 57 & \\
\hline
\end{tabular}


Mandible.-There is noteworthy variation of the mandible only in the height and shape of the coronoid processes. The two sides of the lower jaw of 240002 exhibit asymmetry rostrad. Between the twelfth and thirteenth teeth the height of the left side is 20 , but of the right only $16.6 \mathrm{~mm}$. Accompanying this state of affairs, and very likely having caused it, is a perforation of the lateral aspect of this portion of the jaw, now continuous with the dental canal, and probably indicating a former abscess at this point. It should also be noted that in this specimen the superior portion of the symphysis menti is indented or partially cleft, and within the angle so formed there are two small teeth upon the right side and one on the left.

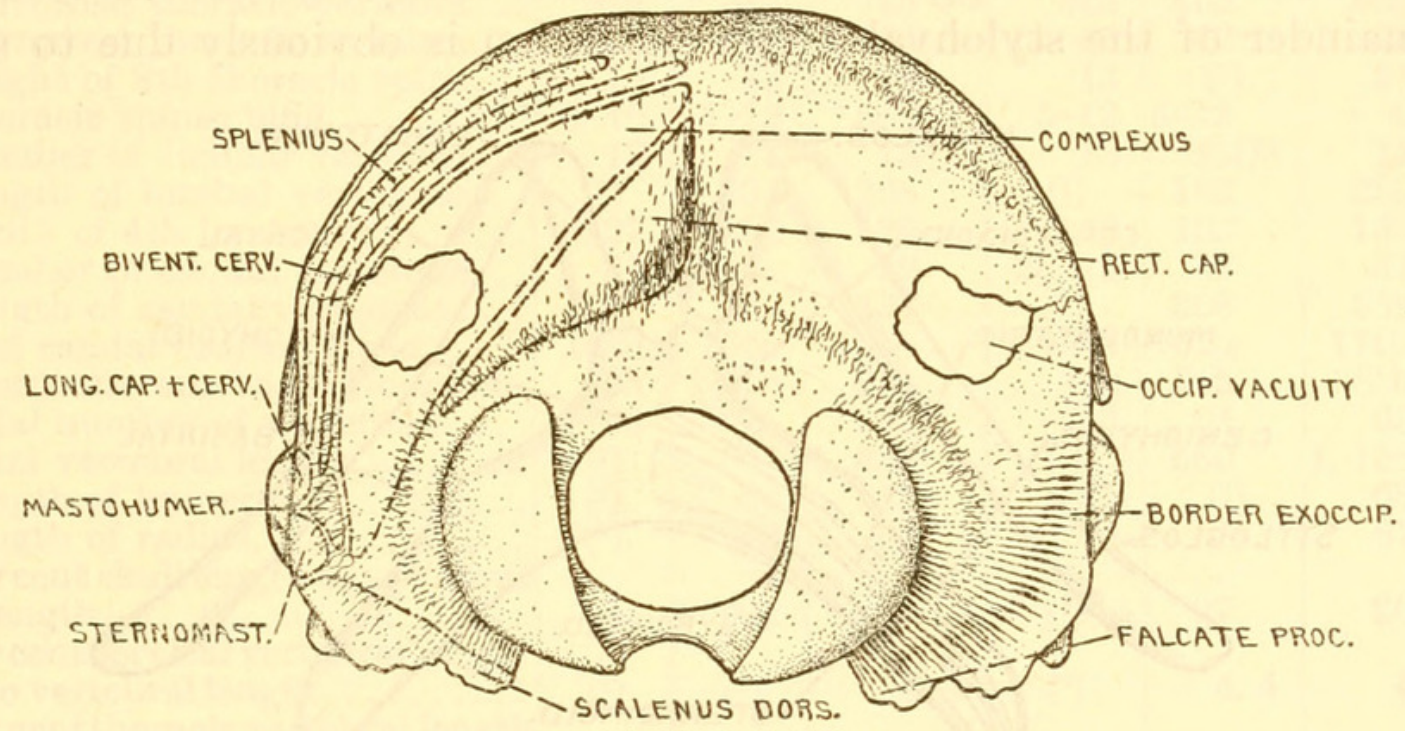

Fig. 3.-Posterior aspect of the SKull, Showing position of Muscle ATTACHMENTS

This condition may very likely prove of significance in a study of the dentition of the toothed whales.

Teeth.-The number of the teeth in Neomeris is unstable and too variable to be of much diagnostic value. Either tooth row of the maxillary series may vary from 16 to 21 in number, and of the mandibular from 15 to 20 . My figures are essentially in accord with those of Allen, save that in two of my skulls the right mandibular series numbers 20 teeth in one and 21 in the other, while in the individuals examined by him the greatest number in either side of the lower jaw was 19 . The youngest skull of the present series has the largest number of teeth, and because of the crowded condition they overlap shingle-wise.

The hyoid complex exhibits the form shown in figure 4 and consists of five bones. As herein termed, these comprise the body or basihyal; the two ceratohyals attached upon the anterior portion of the body; and in further sequence the two stylohyals. There is con- 
siderable variation in the precise shape of the basihyal, which, in the older specimens at hand, has a spread of from 85 to $98 \mathrm{~mm}$. There is equally great variation in the length of the ceratohyals, and in two specimens the left one of this pair is definitely the longer. The stylohyals are about four times as long as these, and their terminal portions fit into depressions upon the border of the exoccipitals.

At roughly $20 \mathrm{~mm}$. from the distal end of the stylohyals is a considerable thickening of the bone which might at first glance be considered to have resulted from muscle stress. Reference to No. 240001 indicates, however, that such is not the case, for this portion of both bones is "staggered" craniad and obliquely ossified to the remainder of the stylohyal. This condition is obviously due to an

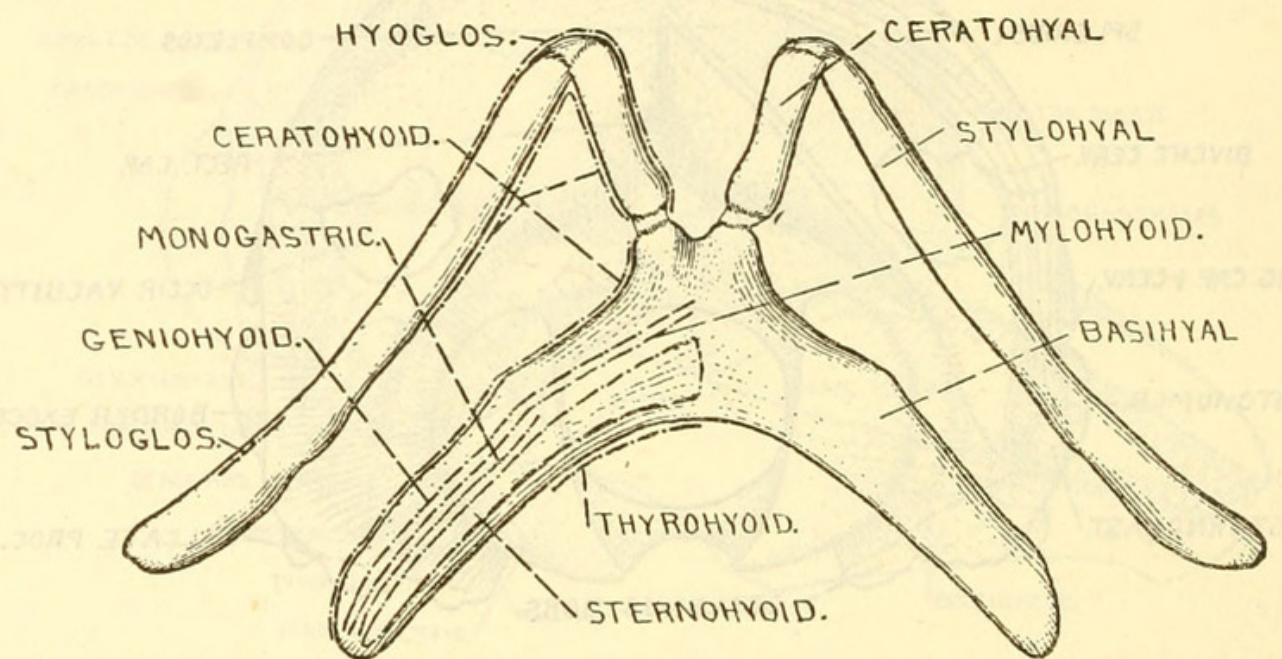

Fig. 4.-Hyoid COMPLEx OF NeOMERIS, SHOWING POSITION OF MUSCle ATTACHMENTS

irregularity in the position or relation of the centers of ossification concerned, and could hardly have been caused by any early fracture. The evidence, therefore, seems practically conclusive that what is here termed the stylohyal is a composite bone consisting of two components that originally represented a tympanohyal and a stylohyal. The ceratohyal as here designated, therefore, probably contains elements of both this bone and an epihyal. I believe that the latter is usually the one of this pair that first shows the effects of eliminating or reducing influences, but whether this is actually the case in the present instance can be determined only from embryological evidence.

In presenting vertebral measurements it must be borne in mind that the intervertebral cartilages, or at least many of them, have been eliminated during cleaning of the skeleton, and hence these measurements are an indeterminate degree smaller than would have been the case could they have been taken before preparation of the 
skeletons. In addition, most of the epiphyses, both anterior and posterior, of numbers 239990 and 240003 have been separated in cleaning and the vertebral measurements of these specimens are consequently worthless for comparison.

Body and apendageous measurements (in millimeters) of the skeleton

\begin{tabular}{|c|c|c|c|c|c|c|}
\hline Osteological detail & 239990 & 240001 & 240002 & 240003 & 240862 & 49544 \\
\hline 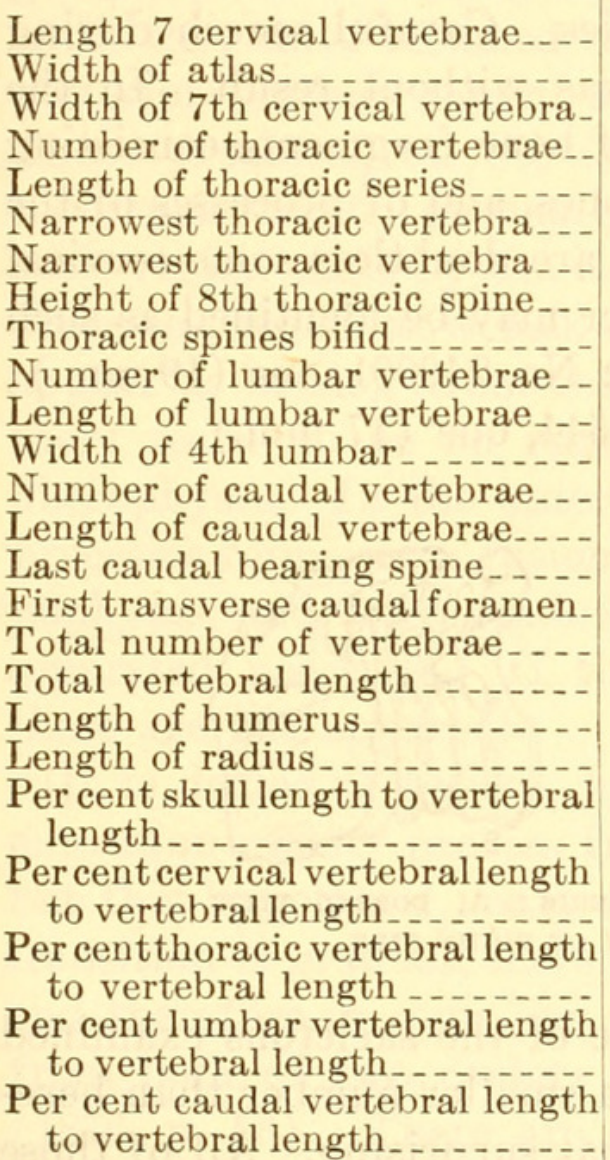 & $\begin{array}{c}46 \\
93 \\
59 \\
12 \\
(1) \\
8 \text { th } \\
53 \\
15 \\
6-10 \\
13 \\
(1) \\
127 \\
31 \\
(1) \\
16 \text { th } \\
7 \text { th } \\
63 \\
(1) \\
(1) \\
(1) \\
(1) \\
(1) \\
(1) \\
(1) \\
(1)\end{array}$ & $\begin{array}{c}33 \\
93 \\
57 \\
12 \\
267 \\
8 \text { th } \\
50 \\
13 \\
5-12 \\
12 \\
335 \\
138 \\
(1) \\
(1) \\
16 \text { th } \\
8 \text { th } \\
(1) \\
(1) \\
62 \\
72 \\
(1) \\
(1) \\
\left({ }^{1}\right) \\
\left({ }^{1}\right) \\
\left({ }^{1}\right)\end{array}$ & $\begin{array}{r}46 \\
91 \\
58 \\
12 \\
257 \\
7 \text { th } \\
54 \\
12 \\
5-8 \\
13 \\
298 \\
136 \\
29 \\
437 \\
16 \text { th } \\
8 \text { th } \\
61 \\
1,038 \\
55 \\
62 \\
\\
21 \\
4.4 \\
25 \\
\\
29 \\
42\end{array}$ & $\begin{array}{c}47 \\
91 \\
70 \\
12 \\
(1) \\
8 \text { th } \\
51 \\
13 \\
5-12 \\
13 \\
(1) \\
140 \\
28+3 \\
(1) \\
16 \text { th } \\
7 \text { th } \\
63 \\
(1) \\
61 \\
65 \\
\\
(1) \\
(1) \\
\left({ }^{1}\right) \\
(1) \\
(1)\end{array}$ & $\begin{array}{c}30 \\
75 \\
(1) \\
12 \\
160 \\
8 \text { th } \\
42 \\
(1) \\
5-12 \\
13(?) \\
182 \\
102 \\
32 \\
308 \\
16 \text { th } \\
7 \text { th } \\
64 \\
680 \\
(1) \\
(1) \\
\\
27 \\
4.4 \\
24 \\
\\
27 \\
45\end{array}$ & $\begin{array}{r}53 \\
95 \\
69 \\
13 \\
280 \\
6 \text { th } \\
60 \\
21 \\
0 \\
12 \\
289 \\
158 \\
31 \\
536 \\
17 \text { th } \\
8 \text { th } \\
63 \\
1,158 \\
66 \\
67 \\
\\
20 \\
\\
4.5 \\
24 \\
\\
25 \\
46\end{array}$ \\
\hline
\end{tabular}

\footnotetext{
1 Detail imperfect.
}

Cervical vertebrae.-The first three cervical vertebrae of Neomeris are completely fused and the remaining four are free, though exceedingly thin. The measurement of length of the cervical vertebrae was taken from the inferior notch of the atlas to the posterior epiphysis of the seventh vertebra. It represents only about four and one-half per cent of the total vertebral length. The atlantic complex is exceedingly variable in a variety of ways. The transverse processes of the atlas and axis show great differences in development and conformation, but not much in total width. Another detail exhibiting much variation is the precise position of the dorsal lamina of the atlas with respect to the remainder of this complex, for in some specimens it is situated much more craniad, relatively, than in others. The inclination of the transverse processes of the seventh vertebra, as well as the greater total width at this point as compared 
to that of the fourth, fifth, and sixth vertebrae, is also quite variable. This seventh vertebra has a costal facet for the capitular attachment of the first thoracic rib.

Allen writes (p. 250) that in all five of the specimens which he examined, as well as in Temminck's example, there was a pair of small accessory ribs in connection with the seventh cervical. In 240864 there was a pair of these cervical ribs attached by syndesmosis or shreds of fibrous tissue to the ventral aspect of the transverse processes of the seventh vertebra of this series. Careful search during dissection for cervical ribs in 240862 was without result. In the skeletons before me there are a number of bone fragments consisting of small pieces of broken ribs, chevron bones, and of processes of the vertebrae. Indistinguishable from these are doubtless some cervical ribs; but the only ones in which the latter may be identified as such with satisfactory certainty are as follows: No. 240001, one (19 mm.); 240002 , two (19.2 and $18.5 \mathrm{~mm}$.) ; and 49544, one (17 mm.).
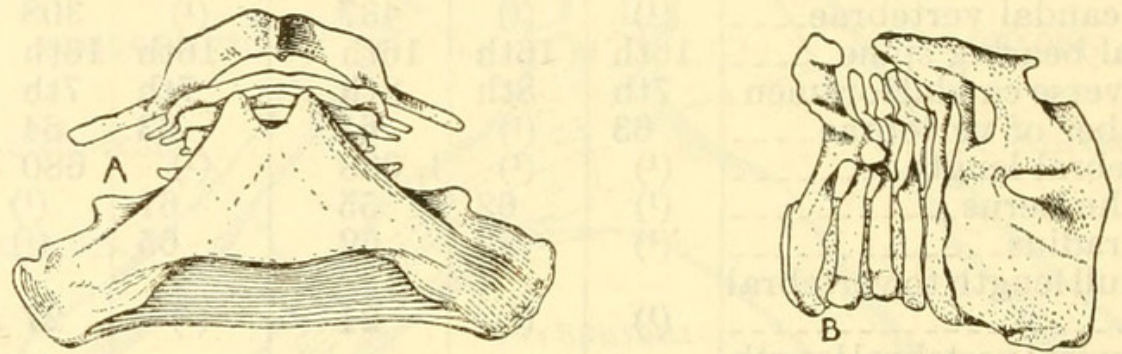

Fig. 5.-Cervical vertebrae of neomeris: A, dorsal view FACING CAUDAD; B, LATERAL VIEW OF RIGHT SIDE

Thoracic vertebrae.-The fact that five of the skeletons examined have but 12 thoracic vertebrae, which is a smaller number than heretofore recorded for this genus, is somewhat surprising. All of those considered by Allen had 13 save the one reported by Lydekker, which had 14. But one of the animals studied by me has 13 vertebrae in this series, while one (No. 240864, which was not cleaned) has 14. This series varies from 24 to 25 per cent of the total vertebral length.

The homology of certain of the vertebral processes of the Cetacea is a matter of some dispute, but the question certainly can not be settled until a thorough study of all known fossil as well as recent forms has been made. In those cetaceans in which the serial transition of the lateral vertebral processes is abrupt, as Hyperoodon and Mesoplodon, the question of homology is a different matter, which does not here concern us; but in Neomeris, which in this respect is comparable to the majority of whales, the conditions are tentatively believed to be as follows:

The centra of the first six thoracic vertebrae, as well as the seventh cervical, have facets for the capitular attachment of the first seven cervical ribs. There are no certain indications of parapophyses asso- 
ciated with these facets, nor upon the centra of the vertebrae posterior to these. As with the remaining vertebrae of this series, the transverse process ${ }^{2}$ of the first thoracic has a facet for the tubercular attachment of the first thoracic rib, but cranio-mediad thereto is a slight bony swelling. In each transverse process of the vertebrae, succeeding in caudal sequence, this swelling is larger, sharper, and farther removed from the tubercular facet. They also migrate gradually farther mediad and craniad until at about the ninth or tenth they have assumed the position of metapophyses, and in the posterior lumbar region, are situated dorsad of the neural canal. Those processes, on the other hand, upon which are located the tubercular facets, gradually migrate ventrad in the posterior thoracic region until by the time that the third lumbar is reached, the processes, which now lack the facets for articulation with the ribs, appear as arising from the centra. The transition is gradual and there seems to be no reason for considering them as other than diapophyses. In the anterior thoracic region, then, the transverse processes represent a fusion (or lack of separation) of met- and diapophyses, and these gradually separate to form distinct and widely separated processes. If there be parapophyseal elements present, these are not apparent.

It is denied, I believe, by many embryologists that there can be migration of any process from one center of ossification to another, but this hypothesis needs very convincing proof. In Neomeris the transition is gradual, there certainly appears to be such a migration, and therefore in some one vertebra this lateral process must spring from both of two centers of ossification, as illustrated by Flower $(1876$, p. 53). There are often shifts in the positions of muscles, and most processes are merely osteological indications of muscular stresses.

Craniad of the point at which the metapophyses become closely associated with the laminae of the adjoining vertebra there are fairly well developed postzygapophyses, but these disappear as processes farther caudad.

The vertebra of the thoracic series whose total width measures the least varies in position from the sixth to the eighth, and in breadth, from 42 to $60 \mathrm{~mm}$. Craniad and caudad this measurement increases. The neural spines of this series, in any one individual, are all of approximately equal height, that of the eighth varying from 12 to $21 \mathrm{~mm}$. (measured from the superior border of the neural canal) according to age, and possibly the sex of the individual. The spines of the anterior caudal vertebrae are directed straight dorsad, while both anterior and posterior to this region they are inclined some-

2 The term transverse process is used herein merely in its physiographic sense to denote the most prominent lateral process of any vertebra. 
what caudad. Due apparently to the incomplete fusion of the two halves of the vertebral arch as these develop from their respective centers of ossification, some of the thoracic spines (see table, p. 11) in all of the skeletons save 49544 are partially bifid.

Lumbar vertebrae.-The lumbar vertebrae are usually of such number as to compose with the thoracic series a complement of 25 . Allen lists only two individuals with 25 , one with 27 , and the remainder with 26, while but one of my specimens is in the first-mentioned class. I imagine, however, that the vertebra which Allen considers to be the last lumbar I have placed in the caudal series. The length of the lumbar vertebrae varies from 25 to 29 per cent of the total vertebral length. The diapophyses of the first lumbar are abruptly of considerably greater length than those of the last thoracic. The third, fourth, or fifth of this series is the broadest (the fourth varies from 102 to $158 \mathrm{~mm}$.), and thence caudad to the end of the tail there is a gradual decrease in the length of the diapophyses. The metapophyses are as described under the thoracic vertebrae, and there are no other processes except the neural spines. The more cranial of these are sometimes bifid, but not to the extent found in the thoracic series. In 239990 and 49544 the lumbar spines increase in height caudad, but in the others they are all approximately of the same size and but a trifle, if any, higher than in the thoracic region.

Caudal vertebrae.-There are 32 caudals in one, 31 in three, and 29 in one of the specimens before me. About a dozen of the terminal vertebrae are missing from the tail of 240001 , and by comparison it is clear that there are three absent from that of 240003. Allen states that there are but 26 of this series in 49544, but he overlooked, or else did not have, four (placing the fifth with the lumbar series), and there are really 31 , all unquestionably belonging to this one specimen, for its bones are darker and greasier than any of the others. The writer herein follows what seems to be the usual procedure in studies of cetacean osteology in considering that the first vertebra with facets for the attachment of a chevron constitutes the first of the caudal series. This, of course, is arbitrary, for there is no way of knowing where the cetacean tail actually starts, as in other mammals chevrons do not always begin at the same point in the series. Allen evidently considers that the first vertebra showing chevron facets is the last lumbar, although he does not actually say so. In the only three instances where this could be measured with accuracy the caudal series constitutes from 42 to 46 per cent of the vertebral length.

The more anterior of the caudal spines are the highest of the whole vertebral column, but thence caudad all processes decrease in size in caudal sequence until the terminal dozen are nothing more than bony 
buttons. The last vertebra to have a minute neural canal is the sixteenth in two instances, seventeenth in another, and eighteenth in a fourth. The last vertebra to bear a spine is the sixteenth save in 49544 , in which there may be said to be a small spine present on the seventeenth. The first vertebra to have a small foramen upon the dorso-lateral aspect of either side of the centrum is the seventh in four cases and the eighth in two. The more cranial of the chevron bones are large and well developed, but without my personally having cleaned the skeletons it is imposible to state their exact number with any confidence.

\section{THORAX}

Ribs.-As already stated, there are 12 pairs of thoracic ribs in five of the animals studied, 13 in one and 14 in another. The first seven have both capitular and tubercular attachment, the former being upon the centrum of the vertebra next craniad to the tubercular articulation. This is so in all cases save in one of Allen's specimens in which there were but six ribs in this class. The remaining ribs are attached only to the transverse processes or diapophyses. The first rib is much the stoutest and the others are inclined to become more slender in caudal sequence. The parts of the ribs usually designated as costal cartilages in most mammals are completely calcified. The first pair of these is especially robust and is attached to the sternum in peculiar fashion. In the only individual in which the majority of these sternal ribs are still connected with the sternum there are four pairs directly attached, and a fifth pair indirectly to the extreme caudal portion by cartilage. This seems also to be the case in two of the other specimens before me, while in the remaining three there are probably but three pairs with direct attachment and a fourth with a cartilagenous union; but the ribs are now disarticulated.

Sternum.-The sternal complex consists of a single bone, representing the fusion of an unknown number of component parts. It is shorter and more specialized than in the great majority of cetaceans and there is much variation in its shape, just as illustrated by Allen in the case of his specimens. The measurements of those before me, given in the same sequence as in Table 1 , are 95 by 75 mm., 72 by 79,99 by 82,81 by 78,65 by 56 , and 89 by $83 \mathrm{~mm}$. In each case the first figure given represents sagittal length, and the second, transverse breadth; so it is seen that the sternum may occasionally be broader than long. In two of the present specimens there are sternal fenestrations (caused by lack of ossification between centers) similar to those illustrated by Allen in his Plate 3. The latter also shows the manner of articulation of the first sternal rib, craniad with the cranial process and caudad with the lateral 
process of the sternum, leaving a vacuity between. Most of the sterna are relatively flat, but that of 240002 is much curved in a sagittal direction, the convex aspect being directed ventrad.

The Cetacea have no clavicles.

ANTERIOR LIMB

The scapula is as shown in Figures 6 and 7 , and described by Allen. There is very little variation in the scapula proper, but a great deal, constituting 100 per cent, in the width of the acromial process. The coracoid process is fairly uniform save in 240002 , in which there is a well-marked accessory process extending ventrad. This suggests some sort of muscle attachment, but in the two specimens dissected there was no muscle connected with either of these processes, and in comparison with most cetaceans their development is very weak.

From the prepared specimens it is impossible to secure the length of the fore limb for the reason that some of the more distal elements, including the cartilage, are missing. In the material available the humerus may be practically as long as the radius but it is usually somewhat less (from 86 to 99 per cent). Details of especial interest are the large medial tuberosity, to which are attached the subscapularis and mastohumeralis, showing considerable variation in its precise configuration; and the infraspinous fossa, located toward the cranial border of the lateral aspect. It should also be noted that the distal extremity of the humerus is much flattened in a latero-medial direction, and that the articulation at this point is immovable.

As illustrated, the central portion of the radius is almost twice as broad as of the ulna. The former bone has no prominent features: and the latter, little of interest save the olecranol process, upon which is inserted the very decadent triceps. It is very slightly developed in comparison to that of most whales.

The carpal elements are as figured by Allen (p. 253). There is very little variation save in the degree of ossification, and hence separation, of the different bones, this depending upon age.

The second digit is evidently the longest, and in the only specimen in which the distal end is not missing, it has eight bones, including the metacarpal. It seems that the second phalanx of the pollex is the one last to form, and hence, is entirely absent in the younger individuals.

PELVIC BONES

In 240862 the pelvic bones measure $36 \mathrm{~mm}$. in length and were located barely caudad of vertical to the vulva, being $40 \mathrm{~mm}$. from the midventral line, to which they are approximately parallel, and there- 


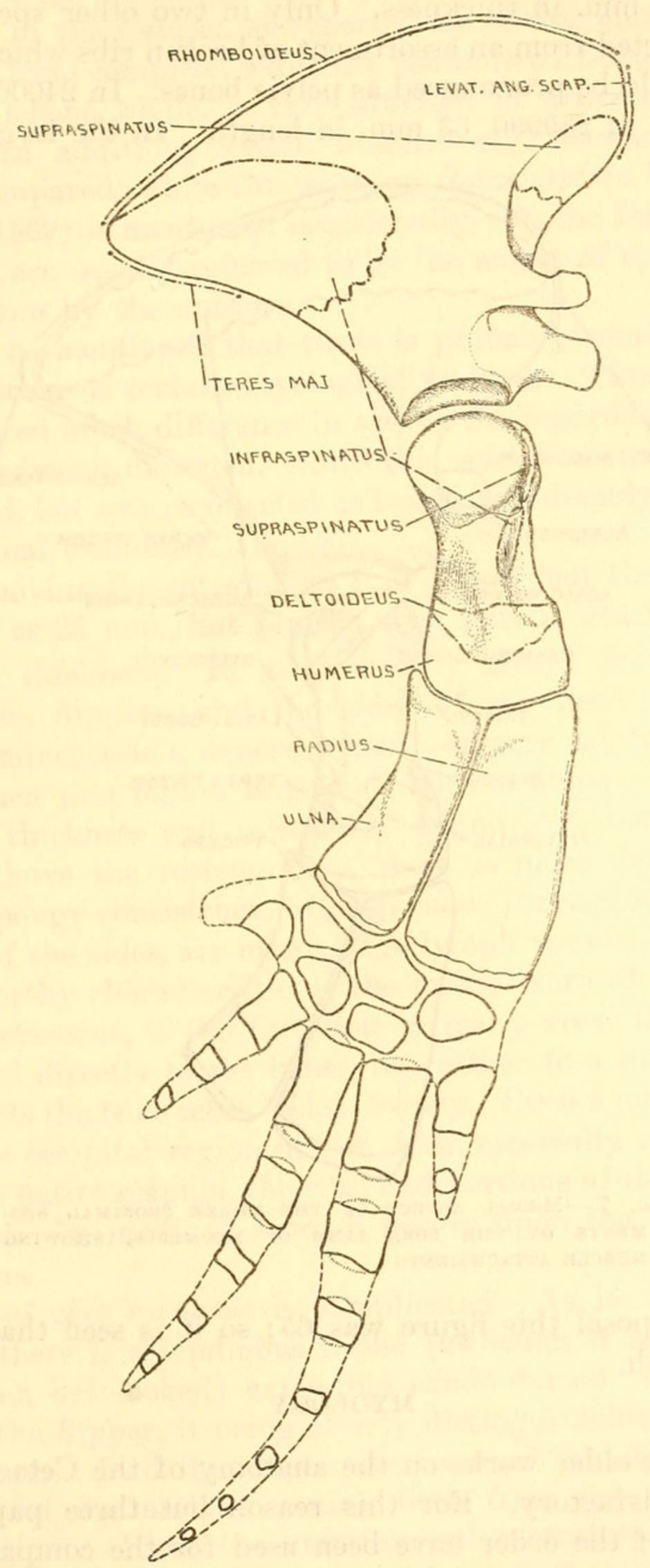

Fig. 6.-Lateral view of fore limb of neomeris, SHOWING MUSCLE ATTACHMENTS 
fore not quite parallel to the body axis. In height they measure 4.5 $\mathrm{mm}$. and $2.5 \mathrm{~mm}$. in thickness. Only in two other specimens could bones be selected from an assortment of broken ribs which with entire certainty could be pronounced as pelvic bones. In 240002 they measure 39.5 , and in $239990,63 \mathrm{~mm}$. in length. In the largest specimen

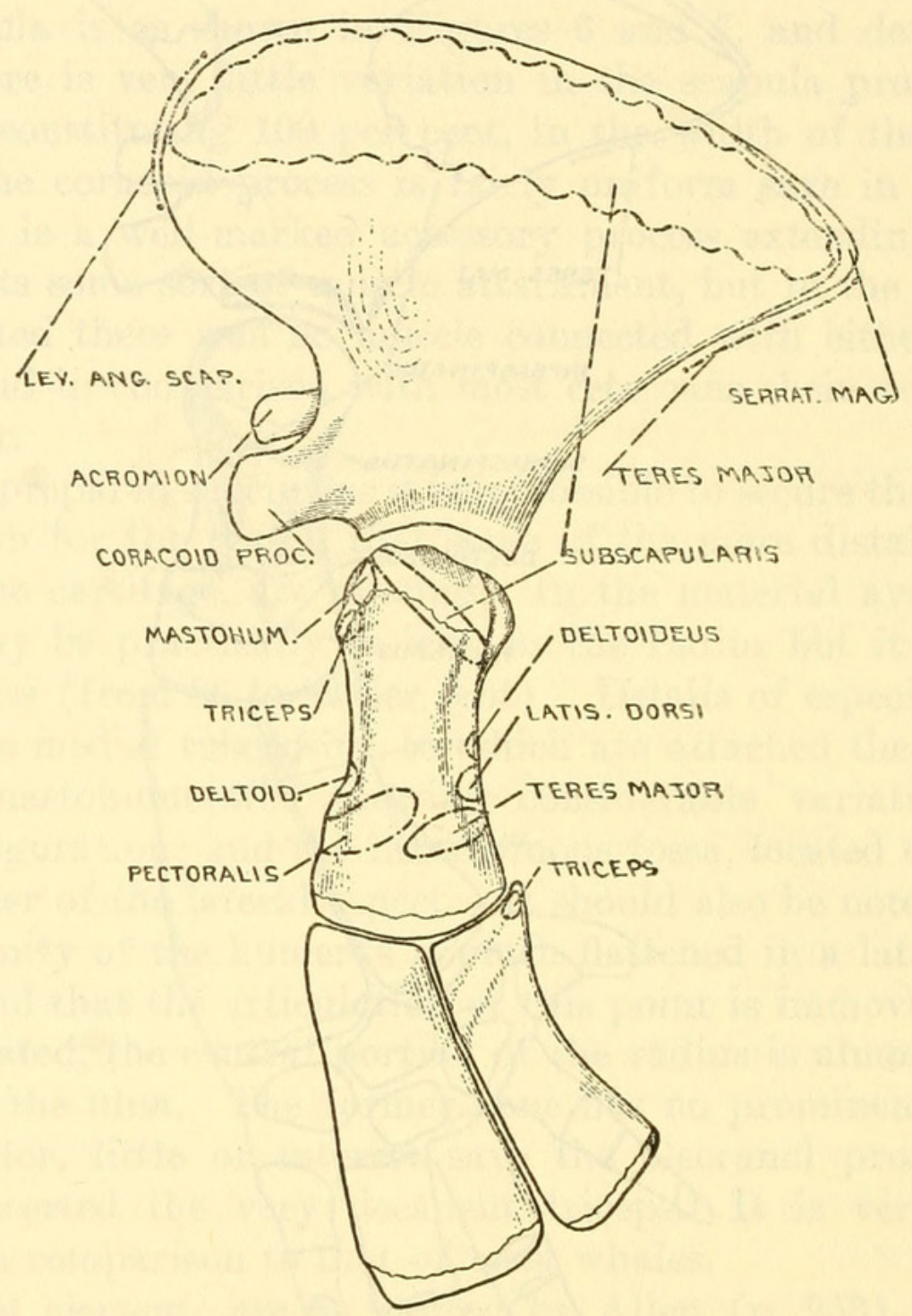

Fig. 7.-Medial aspect of the threv PRoximal SEGMENTS OF THE FORE LIMB OF NEOMERIS, SHOWING MUSCLE ATTACHMENTS

at Allen's disposal this figure was 65 ; so it is seen that they vary much in length.

\section{MYOLOGY}

Some of the older works on the anatomy of the Cetacea are anything but satisfactory. For this reason but three papers on the musculature of the order have been used for the comparison of all details of the musculature of Neomeris. These, given in the order of their value in the present connection, are Schulte's and Smith's work on the muscles of Kogia (1918), Schulte's report on Balaenoptera borealis (1916), and Murie's work on Globiocephala (1873). There 
are features of the latter that are somewhat difficult to reconcile with the anatomy of the Cetacea as reported by others, and the descriptions are far from complete, while the anatomy of Balaenoptera, this being a whalebone whale, is very different in many respects from Neomeris. In addition, certain muscles of Phocaena (Stannius, 1849) are compared, while the work on Balaenoptera by Carte and McAlister (1869) is mentioned occasionally. In the following pages these papers are usually referred to by the names of the genera concerned-seldom by the authors.

It should be mentioned that there is probably considerable individual variation of certain myological features. Thus, direct comparison showed much difference in size of the superficial masseter in the two specimens dissected, while the mastohumeralis was small in the second, but was recollected as being considerably larger in the first individual examined.

After removing the integument it is found that the blubber may be as much as $25 \mathrm{~mm}$., but for the most part is usually 15 or even $10 \mathrm{~mm}$., in thickness. It is practically absent from the lateral peduncle, the flippers, and the sides of the head. Beneath the frontal prominence is a deposit of soft, spongy fat from which the oil runs when this region is pressed with a finger. This is about $50 \mathrm{~mm}$. in thickness and is roughly cylindrical, with bounds illy defined. Above the rostrum, too, there is much fatty tissue, but of tough, spongy consistency. Conspicuous throughout the blubber, especially of the sides, are many large lymph vessels.

A noteworthy characteristic of the musculature of this, and very likely all cetaceans, is the fact that in many areas the muscles are not attached directly to the bones, but rather to a tough membrane which invests the bone more or less loosely. Such a membrane covers most of the occipital region of the skull, especially about the exoccipitals, the entire scapula, the ribs, and portions of the vertebrae are so sheathed. In modified form it occurs upon the hyoid, but not the humerus.

The panniculus carnosus is complicated. As in most if not all cetaceans, there is a tendinous raphe (although it seems sometimes to have been overlooked) extending caudo-dorsad from the caudal border of the flipper, it being clearly distinguishable as such for at least $200 \mathrm{~mm}$. Into this raphe are inserted muscle fibers with a slight cranial inclination running both from the dorsal and the ventral regions. Upon the anterior and central thorax the fibers are not distinguishable until quite well ventrad toward the flipper, but slightly farther caudad they extend from the middorsal line. Here, however, there is interruption of the continuity of the fibers 
between the dorsum and the lateral sheet (fig. 8). In the anterior lumbar region there is no such hiatus, and for a short distance the fibers run from the middorsal line well down over the flank. Ventrad of the axilla the fibers of this muscle extend quite to the midventral line, but farther caudad they do not run so far ventrad. Discernible fibers of the main sheet of the panniculus cease dorsad of the anus; but there are superficial fibers converging to the anus and vulva. These seem to constitute a specialized portion of the panniculus, now segregated from the main sheet and undoubtedly having the function of a compressor mammae. About the mammary orifice there are vestiges of fibers so placed as to constitute a modified sphincter.

Most investigators of the Cetacea have not differentiated a platysma from the panniculus, and the condition of the specimens at hand precluded an attempt at such a division. The suprabrachial portion

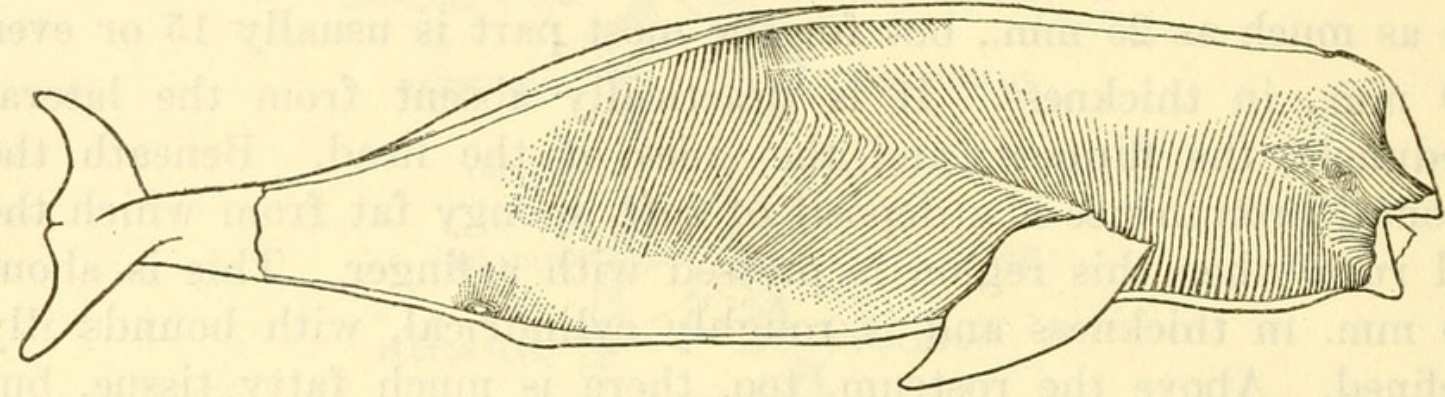

Fig. 8.-Panniculus carnosus and other superficial, SKin musculature of NEOMERIS

of this superficial sheet has origin from the midventral line. The more ventral portion of the muscle is extremely heavy, the fibers being very coarse and loosely joined, with many small cavities of varying size, as large as a couple of millimeters in breadth, throughout the mass. In life these cavities may be filled with soft fat or oil. The consistency of this portion of the muscle is such as to suggest that there may possibly be some glandular action-perhaps certain elements of a specialized submaxillary gland. No parotid gland was encountered. This part of the muscle, then, extends craniad almost to the chin, and the fibers run dorsad to the midlateral region but cease before the eye or ear are reached. Insertion of the panniculus fibers onto the tough, superificial tissue of the brachium is continuous around the entire humerus.

Kogia is figured as having a wider, more extensive raphe running more caudo-ventrad than caudo-dorsad. The panniculus sheet is evidently more extensive, meeting the middorsal and midventral lines for a considerable distance and stretching to the peduncle. Except for the absence of the lateral raphe in Murie's figure the panniculus of Globiocephala seems to be very similar to, although somewhat less 
complicated than, that of Neomeris. Balaenoptera has the raphe prolonged practically to the peduncle, and its panniculus as a whole is simple and much more extensive.

FACIAL MUSCULATURE

As the innervation of the muscles of Neomeris was not attempted, due to the condition of the specimens, the homology of the facial muscles is in doubt, and the names applied to them are either functional or topographical.

For a distance of $25 \mathrm{~mm}$. from the lower lip, upon the entire side of the rostrum, about the eye and in front of the ear, there is situated beneath the skin tough, fibrous tissue so gristly that it could only be whittled away with a very sharp butcher knife, as it was impossible to apply sufficient manual force to an ordinary scalpel for dissection of this tissue. Throughout there extend coarse, specialized muscle fibers, but the whole is too nearly immobile for these to have much if any muscular function. For the reasons stated, no very painstaking dissection of these areas was made. The directions of the fibers were, of course, carefully noted; but the interrelationship of these was very complex.

There is a fairly well defined orbicularis oculi, but the area about the eye is so fibrous that the degree to which this muscle can function is a question. There is also a tough layer extending from the region of the auditory tube with fibers diverging about the eye, and this would probably prove to consist of several muscles. The horny tissue surrounding the lips and extending caudad below the eye evidently represents an orbicularis oris, but this is so hard that it is difficult to understand how the animal opens and closes the mouth with the facility that must be necessary. A few fibers which may possibly constitute a remnant of a depressor auriculae were present, but the homology of these fibers is extremely uncertain.

There is a nasorostralis superficialis originating from the vicinity of the medial portion of the anterior rostrum and running up over the whole face. The toughness of the region, however, causes the primary use of this tissue to be as a shock absorber, with the drawing forward of the anterior lip of the blowhole as a secondary function. The nasorostralis profundus is very similar to the more superficial division, but is less robust, with origin that extends farther along the lateral rostrum. It is less fibrous than the superficial part, but like it the fibers have fascial insertion craniad and laterad of the blowhole.

The original portion of the dilator naris is apparently indivisible. The origin is from in front of the vertex around the margin of the maxilla, from over the supraorbital prominence, and robustly from the cartilagenous tissue ventrad of the lachrymal. 
The insertional portion is, however, divisible into two parts. The pars posticus consists of those fibers originating caudad to an imaginary transverse line passing through the blowhole. Insertion is upon the caudal margin of the latter and for some distance deep to the orifice. The pars anticus arises rostrad of the imaginary line mentioned above and is inserted not upon the dorsal membrane covering the superficial respiratory sac (see p. 39) but upon the lateral and ventral portion of this sac, and upon the dorsal membrane of the deeper sac.

Deep to the anterior part of the dilator is a small layer of fibers, which may or may not constitute an entirely separate muscle. It arises along the ridge situated just laterad of the most anterior of the maxillary foramina, and is inserted lightly upon the ventral membrane of the deeper respiratory sac and into the cartilagenous tissue cranio-ventrad to it. Surrounding the deeper portion of the blowhole, especially rostrad, is fibro-muscular tissue of very fine texture. Because of its situation this must have some mobile function, which one might be inclined to doubt merely from an examination of the tissue.

The facial musculature of Kogia and Balaenoptera seems to be so radically different from that of Neomeris that without knowing the innervation of all or making direct comparisons, an attempt to homologize the muscles would be useless. Murie's figures, but not his text, for Globiocephata show an occipito-frontalis and levator labii superior alaeque naris, which evidently correspond with what are herein termed the two divisions of the dilator naris; and Murie's nasolabialis corresponds in situation to the muscle of Neomeris to which the same term is given; but for Globiocephala the insertion is stated as deep, while in Neomeris it is superficial.

The buccinatorius is quite thin and weak. It originates from between fibers of the nasorostralis and is inserted upon the membrane of the mandible.

Neomeris has a small muscle tentatively termed, because of its position, the tympano-zygomaticus, which stretches from the more ventral portion of the zygomatic process of the squamosal to the tissue investing the ear bone, with fibers running cranio-dorsad. Whatever may be its chief function, it adds strength to the weak articulation of the mandible with the skull. This may possibly be homologous with the depressor mandibulae as described for Kogia and Balaenoptera, but this is considered to be extremely doubtful, as the fibers are directed differently and the function can not be the same.

MUSCLES OF MASTICATION

The masticatory musculature of this animal is very poorly developed and is clearly degenerate. 
The masseter occurs in two divisions. The pars superficiatis has origin from the tissue about the termination of the zygomatic process of the squamosal and the postorbital process of the frontal, and is inserted upon the membranous covering of the ventro-lateral border of the mandible. In the first specimen dissected this division was relatively robust, but in the second its development was extremely slight. Due to the weak origin of this part it can have but slight functional importance. The pars profundus is also small and has origin, not from any bone but from the tough tissue within the orbit and beneath the styliform process. Irisertion is upon the dorsal margin of the mandible adjoining. This division is stronger than the superficial, but yet one is forced to the conclusion that neither plays an important part in the economy of the animal.

The masseter of Neomeris is much smaller than in Kogia and is not involved with the tough, fibrous, superficial musculature of the cheek. The origin is farther caudad than in the latter genus, which changes the inclination of the fibers. That of Balaenoptera seems also to be comparatively somewhat larger, while it is difficult to judge of the development in the figure of Globiocephala.

The temporalis is small and evidently indivisible. It arises from the temporal fossa and passes beneath the postorbital process of the frontal. Insertion is upon the border and adjoining lateral face of the coronoid process of the mandible.

Comparison of the skull of Neomeris with those of Kogia, Globiocephala, and Tursiops indicates that although the temporal is relatively no broader in the three last-mentioned genera, it is much deeper and more robust. Comparison of the skull of Neomeris with that of Balaenoptera is hardly practicable, due to the difference in size; but Schulte's figure indicates that the temporal is broader in the last-mentioned genus. The temporal of Neomeris, in fact, must be regarded as slightly developed and correspondingly weak.

No separation of the pterygoideus was possible in the present animal. Origin is from the membrane investing the falcate process and the portion of the border of the pterygoid bone adjoining, as far rostrad as the notch for the passage of the internal auditory tube. Insertion is not upon the mandible, but upon the tough tissue near the ear bone. Hence, this muscle is nonfunctional as far as its usual duties are concerned, but it may have some use in connection with the neighboring trabeculated air sinus.

In Kogia the pterygoid is not only described as double, but the internal division is again separable. Insertions of all are upon the mandible, and they seem to be well developed. Schulte found the muscle to be double in Balaenoptera also, but Carte and McAlister reported it as single in the same genus. The former authority 
stated that only the internal division reaches the mandible, the external portion having insertion upon the cartilage adjoining. This muscle is neither figured nor mentioned for Globiocephala.

INTERRAMAL MUSCULATURE

The powerful monogastricus, or rostral belly of the more usual digastricus, has origin from the lateral $30 \mathrm{~mm}$. of the basihyal, and insertion along practically the entire medial margin of the mandible. Its original end is especially heavy.

Schulte terms this muscle the hyomandibularis. In Kogia the origin was just twice as long, relatively speaking, for it was from the entire basihyal instead of the terminal half. And in this genus the insertion is much more restricted than in Neomeris. Balaenoptera has a very large muscle associated with the cavum vertrale, which Schulte terms the sternomandibularis. His description of this is so complicated that to a reader it is somewhat ambiguous. He finds that it is imperfectly divisible, and one of the slips he considers to be homologous with the anterior belly of the digastric. An opinion of value certainly can not be offered without examination of a specimen, and no further discussion is here attempted. The anterior belly of the digastric of Globiocephala is figured as being large, but evidently with a more restricted insertion than that of Neomeris.

With strong origin from the entire border of the basihyal and from the usual medial raphe, the fibers of the mylohyoideus extend cranio-laterad to an insertion along the medial margin of the mandible. This type of mylohyoid seems to be rather uniform in the Cetacea.

MUSCLES OF THE TONGUE

The slender and rather weak styloglossus has origin from the cranial border of the stylohyal some $20 \mathrm{~mm}$. from its termination. It runs practically parallel with the neighboring portion of the mandible and is inserted into the lateral border of the tongue. This muscle seems to be very similar in Kogia, Globiocephala, and Phocaena, but Schulte failed to find it in Balaenoptera.

The hyoglossus has origin from the more cranial portion of the stylohyal and the ceratohyal, with a few fibers from the basihyal. The fibers then converge and extend into the medial part of the tongue.

In Kogia and Phocaena this muscle is very similar to that of Neomeris. In the other two genera considered it seems to be inseparable from the genioglossus. As in Kogia and Phocaena, this muscle has no attachment to the hyoid. Origin is from the tissue of the ventral surface of the pharynx craniad of the hyoid system, and insertion is into the tongue. In Balaenoptera and Globiocephala 


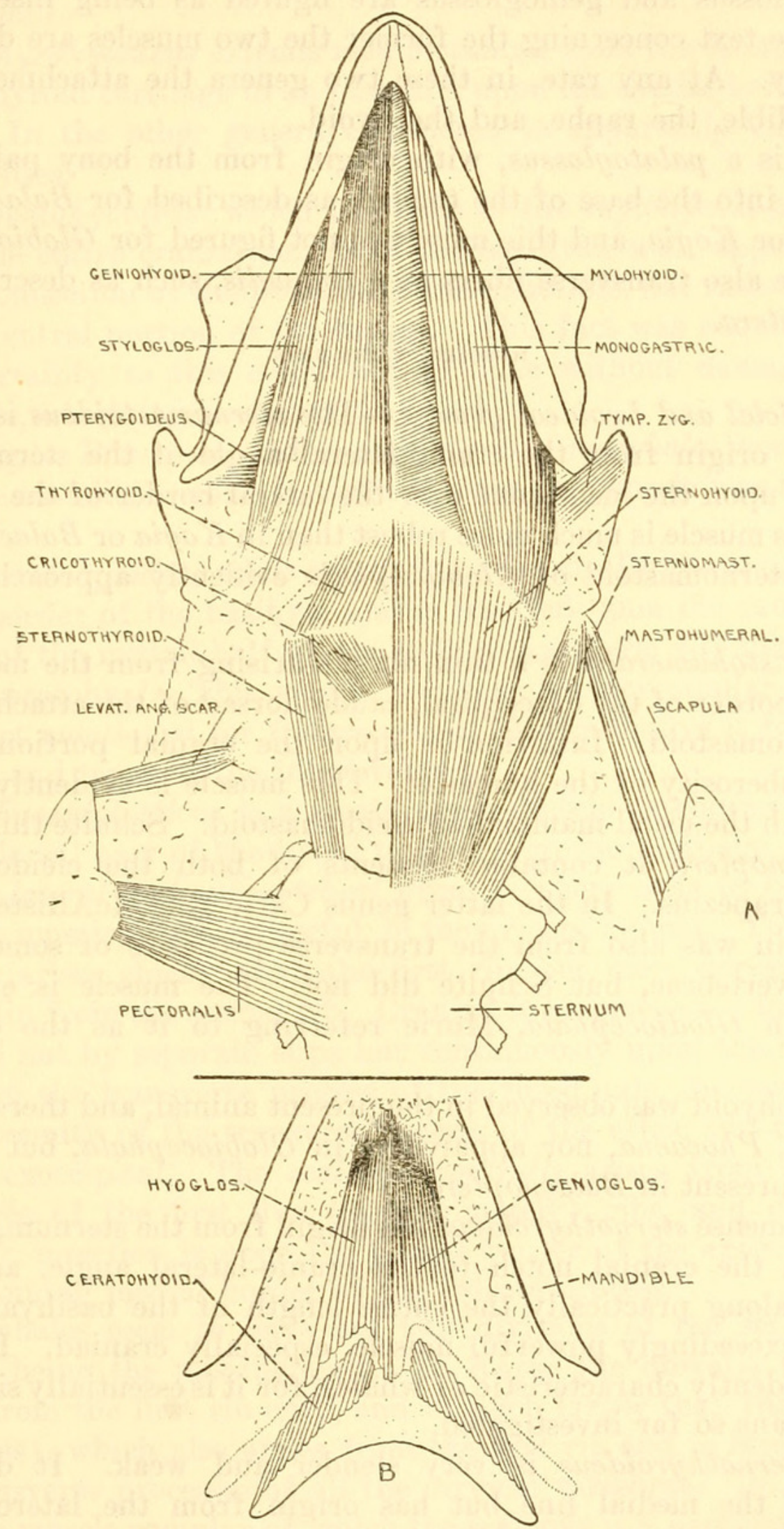

Fig. 9.-Muscles of the ventral aspect of the throat of NEOMERIS: A, MOST SUPERFICIAL MUSCLES (EXCEPT PECTORAL) TO RIGHT OF CENTER; NEXT LAYER TO LEFT ; B, DEEPEST MUSCLES OF TONGUE 
the hyoglossus and genioglossus are figured as being inseparable, but in the text concerning the former the two muscles are described separately. At any rate, in these two genera the attachment is to the mandible, the raphe, and the hyoid.

There is a palatoglossus, with origin from the bony palate and insertion into the base of the tongue, as described for Balaenoptera but not for Kogia, and this muscle is not figured for Globiocephala. There are also transverse fibers of a lingualis, such as described for Balaenoptera.

MUSCLES OF THE NECK

Superficial and hyoideal groups.-The sternomastoideus is powerful, with origin from the cranio-lateral angle of the sternum and insertion upon the membrane over the lateral border of the exoccipital. This muscle is much more robust than in Kogia or Balaenoptera, but the sternomastoid of Globiocephala evidently approaches it in size.

The mastohumeralis is a thin muscle arising from the membrane over the border of the exoccipital, caudo-dorsad of the attachment of the sternomastoid. Insertion is upon the cranial portion of the medial tuberosity of the humerus. This muscle is evidently homologous with the usual mammalian cleidomastoid. Schulte thinks that in Balaenoptera it contains elements of both the cleidomastoid and the trapezius. In the latter genus Carte and McAllister found that origin was also from the transverse processes of some of the cervical vertebrae, but Schulte did not. The muscle is evidently present in Glodiocephala, Murie referring to it as the cephalohumeral.

No omohyoid was observed in the present animal, and there is none in Kogia, Phocaena, nor apparently in Globiocephala, but Schulte found it present in Balaenoptera.

The immense sternothyroideus has origin from the sternum, extending from the cranial notch to the cranio-lateral angle, and it is inserted along practically the entire length of the basihyal. It is thus an exceedingly powerful muscle, especially craniad. Its large size is evidently characteristic of whales, for it is essentially similar in all cetaceans so far investigated.

The sternothyroideus is very slender and weak. It does not approach the medial line but has origin from the latero-cranial process of the sternum, and is inserted upon the lateral portion of the thyroid cartilage. This muscle is apparently similar in Kogia, Balaenoptera, and Phocaena, although in the first mentioned genus Schulte states that origin is also from the cartilage of the first rib. The illustration for Globiocephala shows this muscle as enormous, to such an extent that I suspect there may have been an error made 
in the lettering and what is marked as this muscle is really the sternohyoid.

The thyrohyoideus extends medio-craniad from the lateral portion of the thyroid cartilage to an insertion upon the caudal border of the hyoid. In the other genera considered it apparently exhibits no peculiarities.

The geniohyoideus, which lies deep to the mylohyoid, has origin along the entire cranial border of the basihyal, with apparently no direct connection of the fibers with the mandible, but rather into the cranio-ventral portion of the tongue. This fact was not determined with certainty as this could not be done without damage to the mandible, which it was desired to avoid.

In Kogia, Phocaena, and apparently Globiocephala, connection is with the mandible, while in Balaenoptera this muscle was not found at all.

The ceratohyoideus takes origin from practically the entire craniodorsal border of the basihyal and is inserted upon the caudo-dorsal border of the medial half of the stylohyal and the adjoining border of the ceratohyal. This muscle seems to be very similar in Kogia but is not mentioned for Balaenoptera. Murie figures it for Globiocephala and terms it the interhyoideus.

The hyoepiglotticus is a small, short muscle extending from the cranio-dorsal part of the hyoid to the epiglottic cartilage.

Deep lateral and subvertebral group.-There seem to be but two scalenus muscles, both powerful, in the present animal. The scalenus dorsalis arises chiefly from the first rib, but more dorsad there is also a slip from the second rib. Craniad it becomes very thick and is inserted not by separate slips but continuously upon the membrane investing the transverse process of the fused axis, the caudal ridge and extremity of the tranverse process of the atlas, and the border of the exoccipital. The scalenus ventralis arises from the costal cartilages of the first five (approximately) ribs, and converging strongly, insertion is upon the lateral border of the exoccipital and the adjoining medial border of the falcate process.

All whales seem to have but two divisions of the scalenus, the anticus being the missing part. In Kogia the dorsalis (medialis) arises from the first rib only, and is much larger than the ventralis (posticus), which also arises from the first rib and is inserted upon the transverse processes of all the cervical vertebrae. In Balaenoptera the muscle complex of which the scalenus is a part is very much involved, and Schulte's description of the conditions encountered is not particularly illuminating. There are two divisions of the scalanus in this genus also, however. Both seem to arise from the first three ribs, with fibers from additional ribs. For Globiocephata 
Murie shows but a single muscle, although another may be present.

There is a powerful muscle, the deepest of the infravertebral muscles of the cervical region, which is probably homologous with the

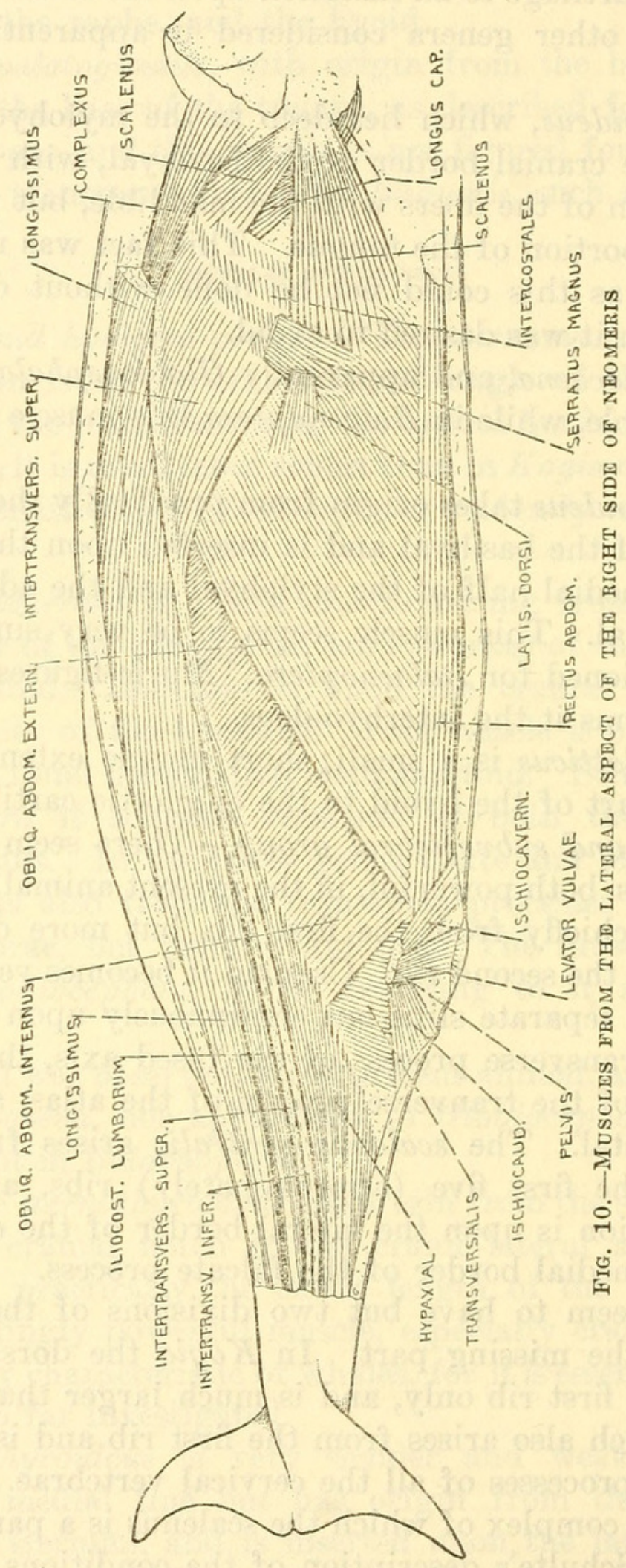

longus capitis (rectus capitis anterior major). In the present specimen this could not be divided, but whether or not this be actually the case, it undoubtedly contains elements of the longus colli, and possibly of the rectus capitis anterior minor as well. It arises from the 
cranio-ventral margins of the transverse processes and bodies of several of the more cranial thoracic vertebrae, and is inserted first upon the expanded ventral portion of the atlas and upon the basioccipital much after the fashion illustrated by Schulte for Balaenoptera. In fact, this muscle mass as a whole appears to be very similar to that of the latter genus: but Kogia has no longus capitis-only a rectus capitis anterior minor and longus colli. Phocaena has all three, as has Globiocephala.

MUSCLES OF THE THORAX

As the sternum of Neomeris is so greatly reduced, the pectoralis is small, and although it may well be divisible, this could not be demonstrated because of the condition of the specimens. There is no scapular attachment. Origin is less than $50 \mathrm{~mm}$. broad, from the lateral fossa of the cranial half of the sternum, with insertion upon the disto-caudal portion of the medial aspect of the humerus.

In Kogia the pectoral is double, with a third slip corresponding to the abdominal pectoral. In this genus the deeper pectoral inserts upon the coracoid, and this is the case in Phocaena as well. In Balaenoptera the muscle is single, as is apparently also the case in Phocaena. In Globiocephala there are two divisions, but the ectal one is shown as many times the size of the ental. In all of these the pectoral mass is very much more extensive than in Neomeris, which is correlated in large part with the fact that the sternum is much the most restricted in the latter.

The serratus magnus or anticus arises by muscle bundles from about the third to the sixth or seventh ribs; but the muscles of this region were in bad condition and the extent of the attachments could be distinguished only approximately. The muscle passes over the more caudal portion of the medial face of the scapula and is inserted upon the scapular membrane for a short distance in either direction from the glenovertebral angle. It is weak in its development.

As might be expected, origin of this muscle is variable among the Cetacea. In Balaenoptera Schulte states that origin is from the fourth, fifth, and sixth ribs, while for the same genus Carte and McAlister found it coming from the eight most caudal ribs, with a slip from the second. In Kogia, however, origin is from the first three ribs, while in Phocaena it extends to the fifth. Murie states that in Globiocephala this muscle extends from the transverse process of the atlas to well toward the caudal part of the thorax, but this seems questionable. Insertion is very similar in all.

No attempt was made to investigate the intercostal or sternocostal muscles. 
The rectus abdominis is a heavy muscle, but the origin is very weak for its size, and is neither from the pelvic bone nor from a definite aponeurosis descending cranio-ventrad, as is the case in Kogia, and apparently Balaenoptera as well. Rather do the fibers arise just craniad of the vulva from between the fasciculi of the lateral abdominal muscles. Insertion is upon the caudal portion of the sternum, and very likely from the costal cartilages adjoining. The details of the origin of this muscle in Globiocephala can not be seen in the illustrations of this animal.

The obliquus abdominis externus, with fibers running caudo-ventrad, has origin by bundles from a number of the more cranial ribs about at the junction of the latter with their costal cartilages. The caudal border of the muscle is on a line running from about the twelfth thoracic vertebra to a point just craniad of the vulva, and insertion is upon the sheath of the rectus abdominis.

The obliquus abdominis internus, with fibers running cranio-ventrad, arises from the deep dorsal fascia and several of the more caudal ribs, including the sternal portions. Insertion is upon the aponeurosis continuous with the rectus sheath. At its ventral termination it does not extend posterior to the vulva, and hence at this point it is not located caudad of the external oblique. Its origin, however, terminates about on a line dorsad to the anus.

Both oblique muscles are apparently substantially similar' in the other cetaceans considered.

The transversus abdominis or transversalis, with fibers extending caudo-ventrad, arises from the deep dorsal fascia investing the long system of the back, and from the caudal border of the thorax along the costal terminations. Insertion is upon the deep portion of the rectus sheath and the tissue about the urino-genital orifices. This muscle extends for some distance caudad of the abdominal obliques, and to this extent differs from Kogia.

Judging from the published descriptions it seems that the muscular layers composing the abdominal walls of the Cetacea are somewhat heavier than usual.

Vertebral MUSCUlature

Secondary back muscles.-The trapezius group is lacking. The latissimus dorsi is small and weak. Because of the condition of the specimens the fibers of the original portion could not be followed with satisfactory detail. It springs, however, by bundles from several of the costae, and insertion is onto the medio-caudal part of the humerus distad to its middle. This is essentially similar to the condition in the other Cetacea discussed. 
An attempt to divide the rhomboideus was unsuccessful, possibly because of the condition of the specimens,. This is a large muscle, with origin from the middorsal line as usual and insertion onto the investing membrane of the scapula along the entire vertebral border. The muscle is single in Balaenoptera and apparently in Globiocephala also, but divisible into a superficial and a deep layer in Kogia. In all three the attachments and extent are substantially the same. There is no occipitoscapularis in Neomeris, this genus thus apparently agreeing with Balaenoptera and Globiocephala, but not with Kogia, in which it is present.

There is a very weak levator anguli scapulae or atlantoscapularis. Origin is from the transverse process of the atlas, and insertion upon

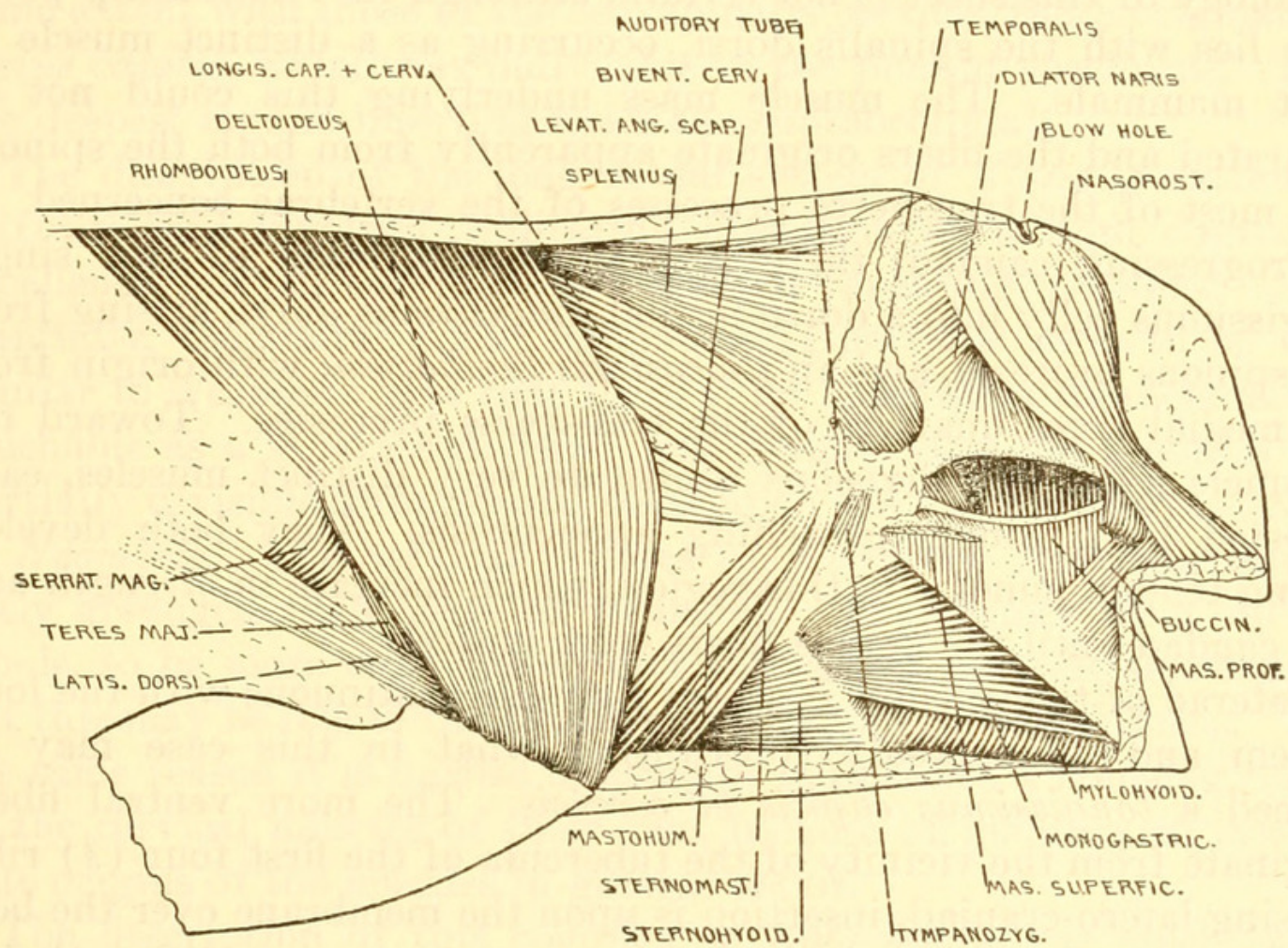

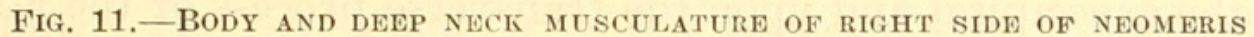

the scapular membrane over the coracovertebral angle and along the border for a short distance ventrad. In the other genera mentioned this muscle is very similar, but there seem to be slight differences in the precise disposition of the insertion.

Intrinsic back musculature.-The splenius is very thin, with origin from some $100 \mathrm{~mm}$. of the middorsal line. The fibers, running cranio-laterad as usual, are inserted upon the occipital in a line extending from $25 \mathrm{~mm}$. laterad of the vertex almost to the squamosal. In Balaenoptera this muscle seems to be thicker but narrower; in Kogia it is both narrow and thin, inserting merely onto the exoccipital; while in the illustrations of Globiocephala it is shown as an immense mass of muscle. 
Definition of the superficial divisions and of the cervical portion of the long system of the back musculature was entirely satisfactory, but preservation was so poor that any disturbance of the deeper portion resulted in the fibers falling apart in inextricable confusion, so that the deeper fibers were not investigated. Equally unfortunate is the fact that the peduncle was somewhat hardened and suffered further desiccation during dissection, so that the tendons in this region could not be precisely followed.

From the ectal aspect the central dorsal region of the longissimus mass of the long system is indivisible save for a thin medial sheet (fig. 11) which may be separated from the underlying fibers from about the sixth thoracic to the third or fourth lumbar vertebra. The homology of this sheet is not certain, although its relationship probably lies with the spinalis dorsi, occurring as a distinct muscle in most mammals. The muscle mass underlying this could not be separated and the fibers originate apparently from both the spinous and most of the transverse processes of the vertebrae concerned.

Progressing caudad, there is gradual separation of this single longissimus belly into a dorso-medial longissimus dorsi, arising from the spinous proceses, and an iliocostalis lumborum, with origin from the medial three quarters of the transverse processes. Toward the peduncle these two divisions constitute very distinct muscles, each invested by a tough, glistening aponeurosis. They both develop strong tendon bundles in this region, which increase in strength and size caudad until the muscle fibers cease entirely.

Laterad of the splenius is a heavy muscle continuous with the long system and undoubtedly constituting what in this case may be termed a longissimus capitis et cervicis. The more ventral fibers originate from the vicinity of the tubercula of the first four (?) ribs. Passing latero-craniad, insertion is upon the membrane over the border of the exoccipital and upon the transverse process of the atlas as well. An effort was made to separate this mass into two distinct muscles on a line between the cervicis and capitis portions, but without success.

Largely deep to the splenius there is a broad muscle continuous craniad with the long system which apparently constitutes a semispinalis capitis. It is separable with ease, and the more, superficial division must therefore be termed the biventer cervicis, and the deeper, complexus. The fibers of the biventer which do not continue directly from the indivisible longissimus have origin from the lateral portion of the transverse processes of several of the thoracic vertebrae and the tubercula of their ribs. Insertion is along the entire supraoccipital from practically the middorsal line to a point on the exoccipital caudad of the zygomatic process of the squamosal. 
The complexus is smaller and lies directly deep to the biventer cervicis. Origin is from the cranial border of the transverse processes of several of the more cranial of the thoracic vertebrae. There is also slight attachment by fasciculi to the transverse process of the atlas. At the insertional end the muscle is very thin but the area of attachment is broad and fascial upon the wide area of the supraand exoccipitals beneath the biventer.

A muscle which seems to correspond with the semispinatis cervicis has origin apparently from the bases of the spines of the first two thoracic and the seventh cervical vertebrae, with insertion upon the caudo-dorsal process of the atlas.

From the last-mentioned situation, with fibers interdigitating to some extent with those of the semispinalis cervicis, there originates a rectus capitis, which was indivisible in the present specimens. It is the deepest muscle inserting upon the supraoccipital.

The description of the long dorsal system of Kogia is extremely intricate and involved, indicating dissection of a high degree of excellence, but not easy to follow without repeating the work. Substantially, the thoracic and lumbo-dorsal portions seem to be very similar to Neomeris save that there is an iliocostalis thoracis distinguishable as a separate division, and Schulte does not mention any partially divisible, thin, medial sheet upon the dorsum such as occurs in Neomeris. The cervical muscles of Kogia are somewhat differently arranged than those of Neomeris. The former seem, on the whole, to be more complicated and specialized, as well as stronger, but this may be due to the condition of the porpoise specimens. For the same reason it is unwise to attempt too precise a homologization of the cervical muscles of these two, because of inability to investigate origins of the muscles in greater detail.

The description of this complex in Balaenoptera is much easier to follow. On the whole, it is not dissimilar to Neomeris. The longissimus, including the capitis portion which Schulte here terms trachelomastoid, is essentially the same. He found the semispinalis capitis to be very much larger, but did not mention its divisibility, save for the deep connection of fasciculi with the underlying muscles. He did, however, find that there was a greater number of deeper cervical muscles than are possessed by Neomeris.

Murie shows a distinct iliocostalis lumborum in Globiocephala, but not a more cranial iliocostal, while both his figures and meager descriptions of the cervical muscles are rather ambiguous. The same applies to Stannius's description of Phocaena.

There has been lengthy discussion of the long, dorsal musculature of the Cetacea by almost everyone who has mentioned the subject, many attempting to subdivide and homologize th 
to an unwise extent. Sufficient is not yet known regarding the anatomy of divers forms of cetaceans for the presentation of a convincing discussion of this sort, and the present writer shall certainly not attempt to add to the confusion of the subject.

Lateral back musculature.-The term transversarii for the two lateral back muscles is open to the objection that it too closely resembles the transversalis of the abdominal region. Murie's designation of supra and infracaudalis can not be criticized on the same grounds, but the names are somewhat ambiguous. Although now apparently distinct from the intertransversarii as we usually know them, the two lateral back muscles evidently constitute a specialization of a part of these, and hence will be termed the superior and inferior intertransversarii.

The intertransversarius superior is in cross section wedge shaped, and the fibers are not arranged in herring-bone pattern as was the case in Kogia. They originate from the terminations and for a short distance upon the dorsal surface of the transverse processes of the lumbo-caudal vertebrae, the muscle being strongly tendinous only toward the peduncle. At the last rib, progressing craniad, a thin sheet of muscle seems to diverge over the more dorsal part of the thorax, terminating at the fifth, fourth, and third ribs, as shown in Figure 11. This is included as a part of the intertransversarius only because it apparently agrees so well with Schulte's figure and description of Kogia. Due to the condition of the specimens, this could not be dissected to my satisfaction. I am neither convinced that it is really a part of this muscle, although the two seem to be continuous, or that it is not homologous with a serratus posterior; but the question must be left unsettled for the present.

Kogia and Phocaena are apparently the only cetaceans heretofore dissected which have this expanded thoracic sheet. Schulte also found a slip of the same muscle extending craniad from the first rib to the occiput dorsad of the scalenus dorsalis. That such a slip may have been present in Neomeris as well, but remained undetected because of the partial decomposition of the specimens, can not be denied. The postcostal portion of this muscle seems to be rather uniform in all the genera discussed, save that in Kogia the fibers are arranged in herring-bone pattern.

The intertransversarius inferior is, throughout its length, a replica of the lumbo-caudal part of its superior neighbor, but it arises from the ventral portions of the teminations of the transverse processes. Craniad, it narrows and ceases at about the last rib.

Postcostal hypaxial musculature.-The hypaxialis of the lumbocaudal region is immense, being in transverse section even more massive than the epaxial or supravertebral muscles. The pedun- 
culate portion consists largely of a bundle of stout tendons, and the attachments are to the chevrons as far as these occur; to the centra; and to the ventral surface of the transverse processes. As the thorax is approached the mass rather rapidly diminishes in size and but few fibers extend craniad of the fourteenth thoracic vertebra.

Broadly speaking, this muscle seems to be very similar in those Cetacea so far investigated, although it must vary much in size. Schulte found that in Kogia and Balaenoptera it is imperfectly divisible into three parts, but the condition of the specimens of Neomeris did not allow of subdivision. It is undoubtedly made up of elements of the psoas, iliacus, and quadratus lumborum muscles.

MUSCLES OF THE ANTERIOR LIMB

As previously mentioned, the whole scapula is encased in a tough, membranous sheet of tissue, and it is to this, and not upon the bone, that the muscles are attached.

The deltoideus is enormous, arising from the scapular membrane along the entire vertebral border. As it passes distad, numerous bundles of tendinous fibers develop upon the superficial belly, and insertion is not only across the whole of the lateral aspect of the humerus, just distad to the center of the shaft, but around both borders and barely onto the medial aspect of the bone. The extent of this muscle is thus over the entire lateral face of the scapula and all but the distal part of the lateral humerus as well. There is no subdeltoideus.

Instead of covering every other muscle of the scapula save a very small portion of the teres major, the deltoid of Kogia and Balaenoptera overlies but two-fifths to a half of the dorso-lateral portion of the scapula, but in Globiocephala it is practically as extensive as in Neomeris. The insertion in the former genus is not given, but in Kogia and Balaenoptera it is less extensive.

The supraspinatus is rather small, originating from the scapular membrane over the supraspinous fossa but not approaching the vertebral border. Insertion is along the cranial border of the head of the humerus. It passes beneath the acromion but has no true attachment to that process.

In Kogia this muscle seems to be smaller and originates chiefly from the medial aspect of the enormous acromion instead of from the scapula proper. In Balaenoptera, Globiocephala, and Phocaena, however, it arises from the usual supraspinous fossa.

The infraspinatus originates from the scapular membrane over a rather irregular area, which approaches the vertebral border only at the glenovertebral angle, and is quite widely separated from the 


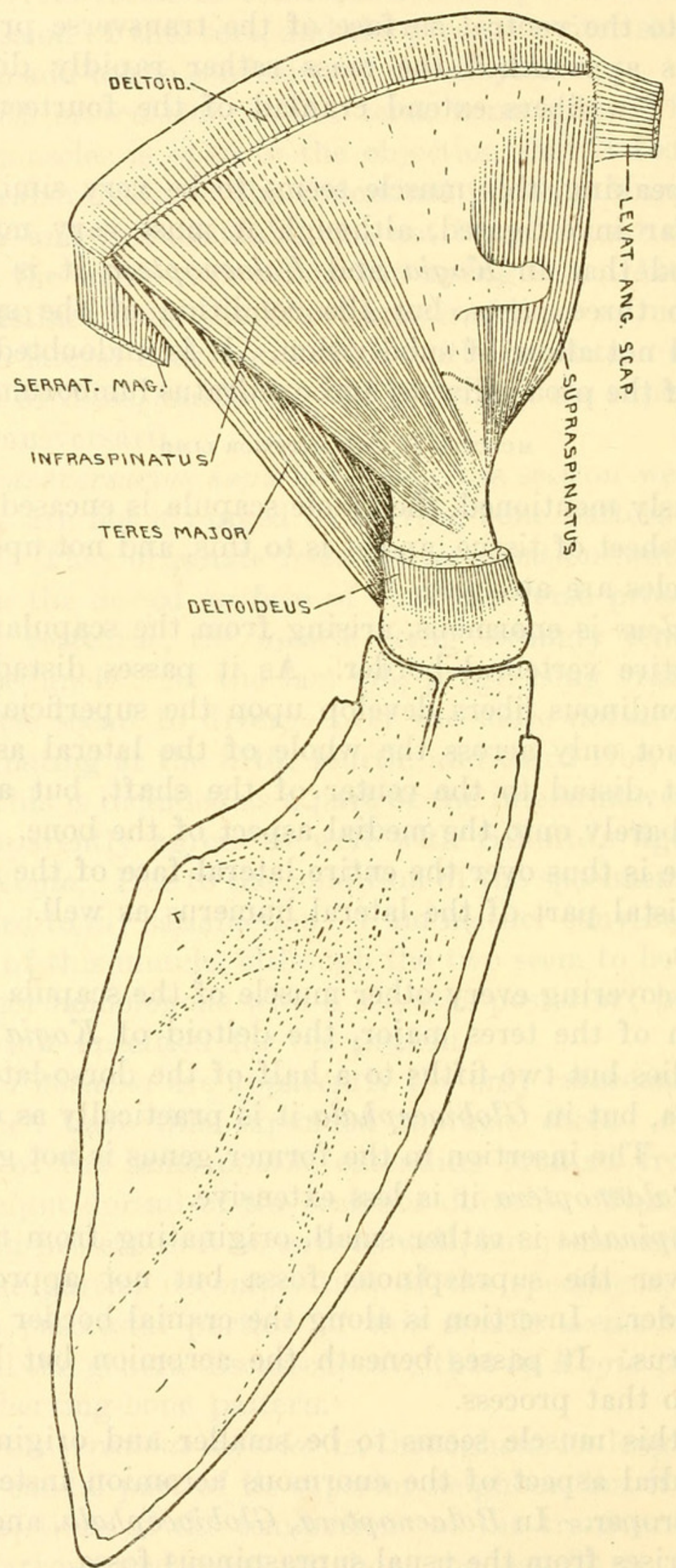

Fig. 12.-Lateral musculature of the right fore LIMB OF NEOMERIS, SHOWING ALSO THE ARRANGEMENT OF THE DIGITAL FIBROUS TISSUE 
supraspinous fossa. The fibers converge, the muscle becomes partly tendinous, and passes over the head of the femur to insertion into the craniolateral infraspinous fossa of the humerus.

In Kogia this muscle is very similar but the insertion is shown as being located slightly more caudad, and is probably weaker. In Balaenoptera the origin occupies the middle of the lateral aspect of the scapula and the insertion is more proximad. It is not fully described nor figured for Globiocephala.

The teres major has origin from the scapular membrane along the axillary border of the scapula adjoining the glenovertebral angle,

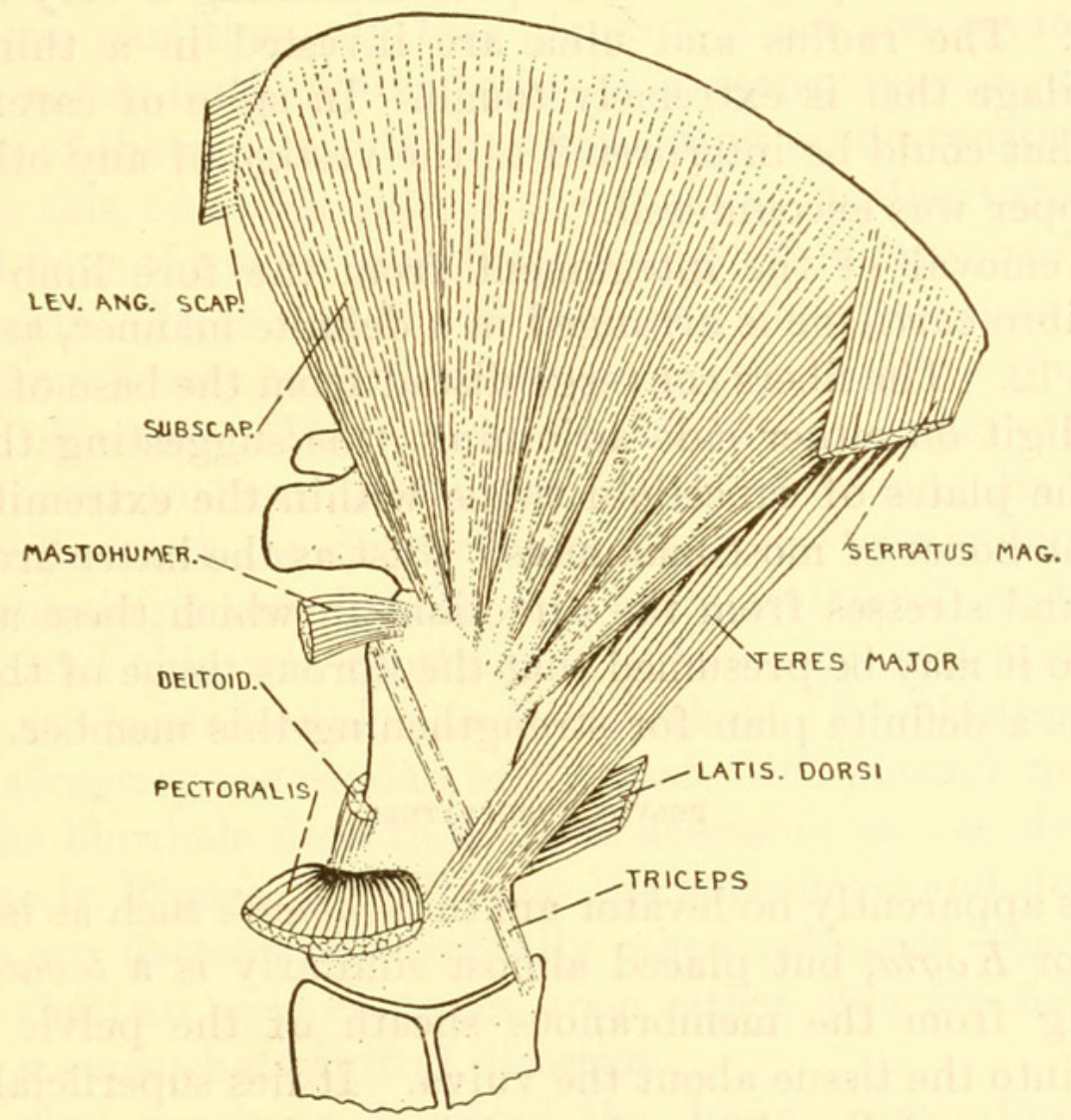

Fig. 13.-Medial musculature of the right Fore limb OF NEOMERIS

and is inserted upon the caudo-distal part of the medial shaft of the humerus.

In Kogia this muscle is apparently somewhat similar, but origin extends a bit farther toward the glenoid fossa; and the insertion is not shown in the illustration. In Balaenoptera the origin is much more extensive, and forms a considerable area over the more caudal part of the lateral aspect of the scapula.

The subscapularis has origin from the scapular membrane near its vertebral border and covers the entire medial aspect of the scapula. It develops strong tendon bundles upon its superficial (medial) belly, but the deeper part is entirely fleshy, and insertion is obliquely upon the tuberosity of the humerus and distad, after the 
manner indicated in Figure 13. In the other cetaceans it seems to be very similar.

The humeral head of the triceps is represented by a remnant of tendon which extends from the cranial portion of the medial tuberosity of the humerus just distad of the attachment of the mastohumeralis, to the olecranol process of the ulna.

There is no muscle attached to either the acromion or the coracoid process, and the remnant of a triceps is the only muscle extending distad of the humerus. The limb of Neomeris is, therefore, unique among the cetaceans so far dissected in having the musculature of this member so simple, in this respect indicating a very specialized condition. The radius and ulna are invested in a thin layer of fibro-cartilage that is extremely tough. In spite of careful search, nothing that could be interpreted as the vestige of any other muscle of the flipper was encountered.

After removal of the integument from the fore limb it is seen that the fibro-cartilage is arranged in a definite manner, as suggested in Figure 12. The fibers converge distad from the base of each digit and the digit on either side adjoining, this suggesting the appearance of the plates of cancelloid tissue within the extremities of the larger limb bones of most mammals. Just as the latter are arranged to withstand stresses from the directions in which these are usually applied, so it may be presumed that the fibrous tissue of the cetacean flipper has a definite plan for strengthening this member.

PELVIC MUSCULATURE

There is apparently no levator ani in Neomeris such as is shown by Schulte for Kogia, but placed almost similarly is a levator vulvae, originating from the membranous sheath of the pelvic bone and inserting into the tissue about the vulva. It lies superficial to a part of the ischiocaudalis. This also originates from the pelvic sheath, with fibers running caudo-ventrad to the midventral line. It is shown for Kogia and corresponds at least in position and direction with the coccygeus of Balaenoptera.

There is a muscle corresponding in position to the ischiocavernosus as given for Kogia. It arises from the pelvic sheath, its fibers interdigitating with those of the rectus abdominis. I doubt if the true ischiocavernosus is as distinct in the female as is this muscle, but it is so termed provisionally.

The deeper parts of the muscles of the anal region were much hardened for some reason, and they were mutilated by the median incision made before the specimens were immersed in the preservative. For these reasons my dissection here was unsatisfactory and no attempt was made to homologize these muscles. 


\section{OTHER SOFT PARTS}

Blowhole.-The blowhole was investigated by cutting thin, horizontal sections from this portion of the head. As the thin, integumentary blubber layer is removed, one encounters upon either side and cranio-laterad to the blowhole proper, a superficial narial dilation or respiratory sac, measuring some $40 \mathrm{~mm}$. in a transverse and 30 in a sagittal direction. It is lined with sooty mucous membrane, the more dorsal portion of which is but slightly wrinkled, while the ventral surface, more especially mediad, is thrown into heavy folds. It is separated from a similar sac upon the opposite side by a thin, membranous partition. In this plane it is not continuous with the blowhole, access to the latter being by a deeper passage situated between two of the rugose folds and extending caudo-ventrad (fig. 14).

Deep to this, on either side, is a second but smaller respiratory sac separated from the more superficial one by a thin layer of fibers of the dilator naris. It is lined with delicate, pink, mucous membrane which becomes sooty toward the passage with which it communicates with the blowhole. The remainder of the accessory air passages and sacs seem to have much individual variation. In the second specimen dissected the deeper respiratory sac communicated, by a passage running caudad, with the extreme lateral portion of the blowhole, and this was continuous with a communication with an accessory sac located caudad to the blowhole. In addition there was a second accessory sac caudad of the first, with passage to the caudal part of the blowhole deep to the first accessory sac, as shown by the dotted line in Figure 14. Whereas the superficial and deep respiratory sacs are flattened horizontally when collapsed (or rather not dilated), the two accessory sacs upon either side are flattened vertically in a somewhat sagittal direction.

In the first specimen dissected the deeper respiratory sac communicated directly with the more rostral accessory sac laterad to, but separate from, the blowhole, while access to the latter was had by a passage upon its caudal wall. There was no second accessory sac whatever.

Finally, there is a lateral dilation of the blowhole upon either side as indicated by the fossa encroaching upon the maxilla laterad of the anterior narial openings of the skull. In both animals the fleshy septum between the nares persisted for only a few millimeters beyond the bone, the remainder of the blowhole consisting of a single air passage without valves or other complications, save as there may be valvular action of the respiratory sacs. In the first specimen dissected the right narial opening of the skull was about 50 per cent larger than the left; in the second specimen the left was some 50 per cent larger than the right. It was naturally presumed that this 
difference in size between the right and left air passages was osteological, but when 240862 had been cleaned it was surprising to find that the size of the two orifices was the same; so the discrepancy was due to differences in the soft parts of the two sides.

Kogia also has two respiratory sacs upon either side, and a number of small, supernumerary pouches which may correspond to the accessory sacs of Neomeris; but the structure of the blowhole is so much more complicated in the former animal, with its spermaceti

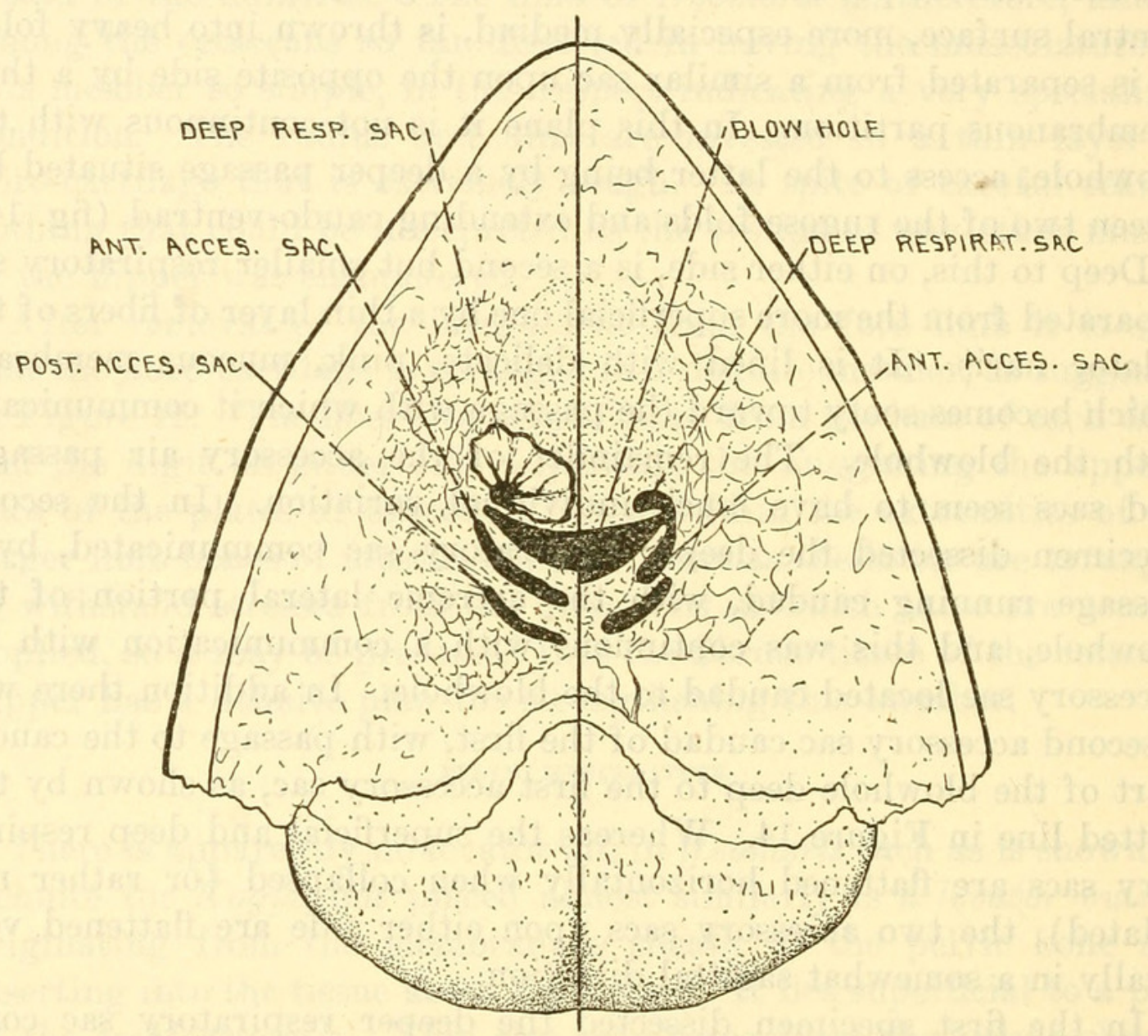

Fig. 14.-Transverse Sections through the frontal region of NeOMeris: SECTION THROUGH DEEPER RESPIRATORY SAC AT LEFT; YET DEEPER SECTION AT RIGHT

organ, that comparison without a specimen is hardly profitable. The details of the blowhole of Balaenoptera are not illustrated, and the description is not particularly clear, but it is gathered that there is a single respiratory sac upon either side. Globiocephala has three pairs of sacs, but they are illustrated as being considerably different from those of Neomeris.

Alimentary tract.-The lips are rounded, leathery, and probably incapable of independent movement because of the tough, fibrous tissue beneath the integument. In the case of the juvenile at hand the teeth have not yet appeared, but there is an alveolar sulcus present. This sulcus still persisted in the immature females dissected, 
although the teeth had appeared above the oral membrane. Even in old specimens, however, the teeth project above the gum to so slight an extent that they can have but little more function than as a slight aid to the holding of slippery prey.

The tongue of the preserved specimens is hard, with a smooth, flat, dorsal surface, an acute border, and somewhat wrinkled, vertical, lateral portion. It is interesting to note that on the anterior part of the acute border there is a well-developed row of papillae. These seem to be softer than the remainder of the tongue and their function is probably tactile.

No dissection of the pharynx was made, but it was noted that the epiglottis was of the type illustrated for Globiocephala.

The stomach is divided into four parts, but one of these is double and so it might with almost equal propriety be considered as consisting of five divisions. The esophagus enters the largest, which is ovoid and about $112 \mathrm{~mm}$. in length. The outer wall is tough and rubbery with a uniform thickness of about one millimeter. The lining, which had peeled loose, was quite heavily plicated and most of it was thin, but surrounding the constricted passage to the second division it was gathered into heavy plicae with a thickness of more than $5 \mathrm{~mm}$.

The second division was flat and somewhat kidney-shaped, measuring 84 by 47 by $22 \mathrm{~mm}$. in thickness. This was lined with extremely heavy, chocolate-colored ridges running lengthwise, these having short rugosities projecting laterad and interdigitating in a regular manner with similar rugosities from the adjoining ridges. At two thirds the distance to the base of this division and hidden between two of the heavy folds is a constricted passage to the third division. In the preserved specimen this had a width not greater than $2 \mathrm{~mm}$. From the second division this passage is absolutely undifferentiated and in spite of careful search it was only by dissecting from the third division that its existence could be demonstrated. The condition of the surrounding parts indicates that the passage is not much, if at all, extensible; and yet it must be, for otherwise the food of the animal would of necessity be limited to such items as the smallest crustaceans, and this, according to the authority of published statements, is not the case.

The third division is double, being somewhat V-shaped with smooth, rubbery lining, each part being about $44 \mathrm{~mm}$. in length, the two being separated by an oval constriction some $10 \mathrm{~mm}$. in greatest diameter.

The fourth division was similar in size and character to one-half of the third and was separated from the latter by another oval constriction, this being but $5 \mathrm{~mm}$. in greatest diameter. 


\section{$2 \mathrm{BHL}$ Biodiversity Heritage Library}

Howell, A. Brazier. 1927. "Contribution to the anatomy of the Chinese finless porpoise, Neomeris phocaenoides." Proceedings of the United States National Museum 70(2662), 1-43. https://doi.org/10.5479/si.00963801.70-2662.1.

View This Item Online: https://www.biodiversitylibrary.org/item/53444

DOI: https://doi.org/10.5479/si.00963801.70-2662.1

Permalink: https://www.biodiversitylibrary.org/partpdf/52010

\section{Holding Institution}

Smithsonian Libraries

\section{Sponsored by}

Smithsonian

\section{Copyright \& Reuse}

Copyright Status: Public domain. The BHL considers that this work is no longer under copyright protection.

This document was created from content at the Biodiversity Heritage Library, the world's largest open access digital library for biodiversity literature and archives. Visit BHL at https://www.biodiversitylibrary.org. 